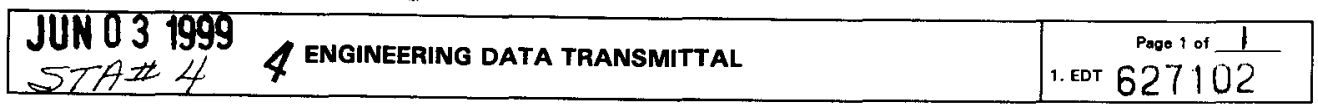

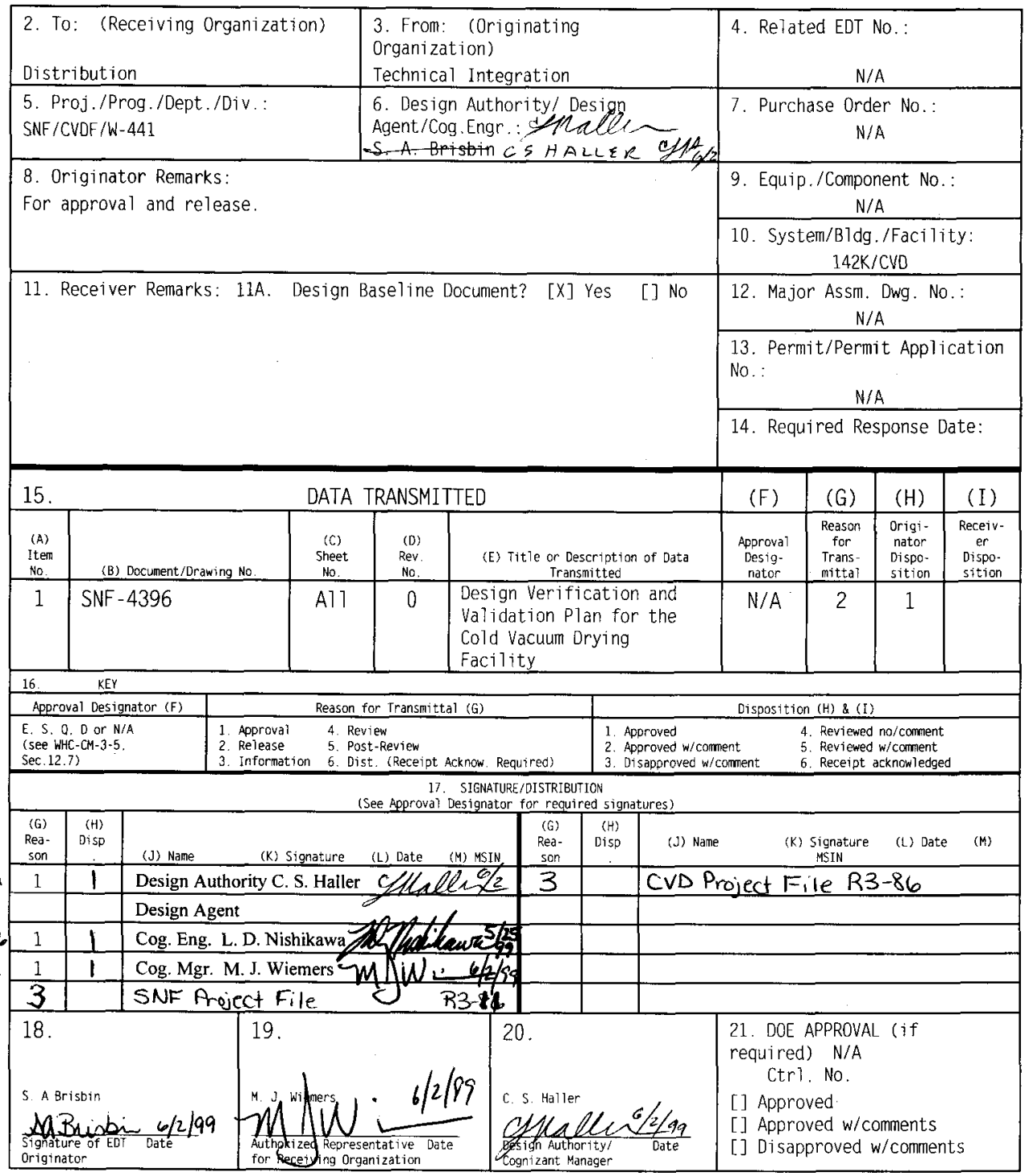

BD-7400-172-2 (05/96) GEF097 


\title{
Design Verification and Validation Plan for the Cold Vacuum Drying Facility
}

\author{
L. D. Nishikawa \\ DE\&S Hanford, \\ Richland, WA 99352 \\ U.S. Department of Energy Contract DE-AC06-96RL13200
}

EDT/ECN: 627102

UC: 510

Org Code: $2 \mathrm{~F} 800$

CACN: 105568

COA: A000

B\&R Code: 39EW70400

Total Pages: 51

Key Words: SNF, CVD, design verification, testing, design review

Abstract: The Cold Vacuum Drying Facility (CVDF) provides the required process systems, supporting equipment, and facilities needed for drying spent nuclear fuel removed from the $\mathrm{K}$ Basins. This document presents the both completed and planned design verification and validation activities.

TRADEMARK DISCLAIMER. Reference herein to any specific commercial product, process, or service by trade name, trademark. manufacturer, or otherwise, does not necessarily constitute or imply its endorsement, recommendation, or favoring by the United States Government or any agency thereof or its contractors or subcontractors.

Printed in the United States of America. To obtain Document Control Services, P.O. Box 950, Mailstop H6372-2420: Fax (509) 376-4989.
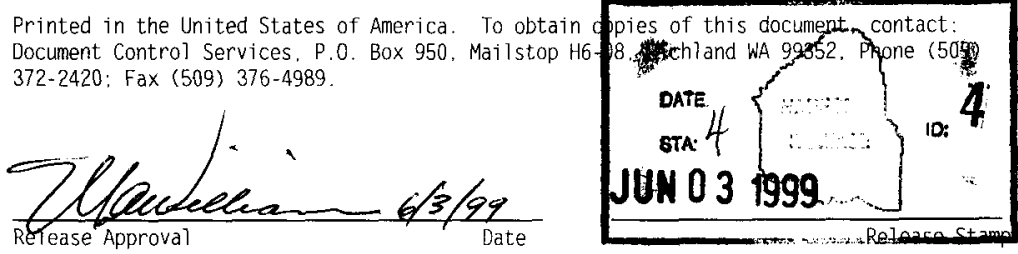


\section{TABLE OF CONTENTS}

1.0 INTRODUCTION AND BACKGROUND....................................................... 3

1.1. PURPOSE AND SCOPE OF PLAN .......................................................... 3

1.2. DESCRIPTION OF DESIGN VERIFICATION AND VALIDATION ............... 4

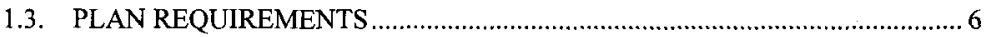

1.4. ORGANIZATION OF PLAN ……………………...................................

2.0 SUMMARY OF REQUIREMENTS AND VERIFICATION DOCUMENTS BY PROJECT PHASE ............................................................................................. 7

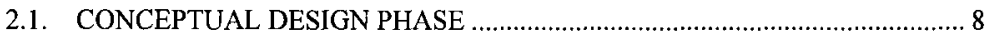

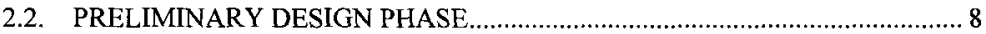

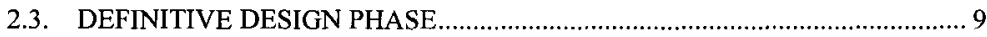

2.4. CALCULATIONS AND SIMULATIONS .................................................. 10

3.0 SUMMARY OF COMPLETED DESIGN VERIFICATION ACTIVITIES.. 10

3.1. CONCEPTUAL AND PRELIMINARY DESIGN ACTIVITIES ...................... 10

3.1.1 FORMAL DESIGN REVIEWS ..................................................... 10

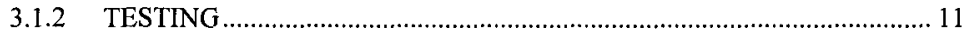

3.2. DEFINITIVE DESIGN VERIFICATION ACTIVITIES .................................. 11

3.2.1 FORMAL DESIGN REVIEWS .................................................... 11

3.2.2 TESTING ...................................................................................... 12

3.2.3 CALCULATIONS AND SIMULATIONS REVIEW ……......................... 13

4.0 COMPREHENSIVE CVD FACILITY FORMAL DESIGN REVIEW .......... 13

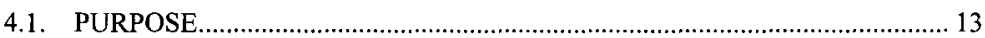

4.2. SCOPE AND LIMITATIONS OF REVIEW .............................................. 14

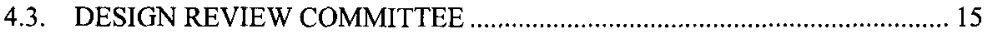

4.4. DOCUMENTS SUBJECT TO REVIEW ……........................................... 15

4.5. REVIEW PROCESS AND GUIDELINES ……........................................... 18

4.5.1 DESIGN REVIEW BRIEFING .......................................................... 18

4.5.2 DESIGN REVIEW CHECKLIST ……............................................... 18

4.5.3 REVIEW AND COMMENT METHODOLOGY ……............................. 18

4.6. DESIGN REVIEW REPORT AND CLOSEOUT ……………........................ 19

5.0 CRITICAL DESIGN PARAMETER VERIFICATION ................................ 19

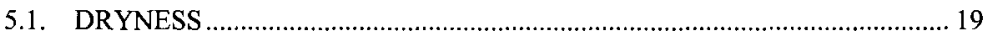

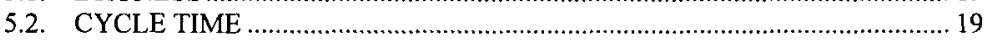

5.3. SAFETY BASIS PARAMETERS AFFECTING CVD OPERATIONS ............ 20

5.3.1 THERMAL RUNAWAY REACTION ……………................................. 20

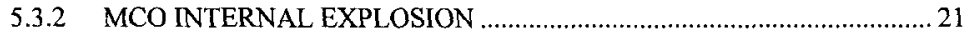

5.3.3 MCO EXTERNAL EXPLOSION ……………...................................... 21

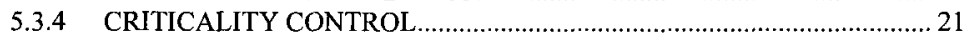

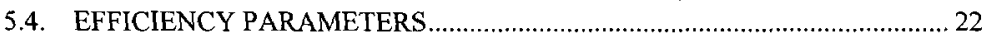

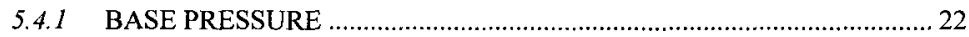

5.4.2 OPERATING TEMPERATURE ........................................................... 22

5.4.3 PARTICULATE GENERATION AND CARRYOVER TO

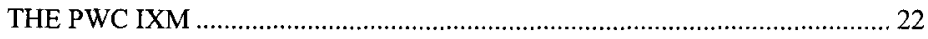


5.5. DOCUMENT SOURCES FOR CRITICAL DESIGN PARAMETER

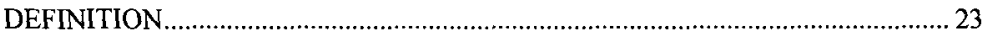

6.0 OTHER CURRENT CVD FACILITY VERIFICATION ................................. 24

6.1. SCIC PRELIMINARY DESIGN REVIEW ……........................................... 24

6.2. CALCULATION VALIDATION AND REVIEW ........................................... 24

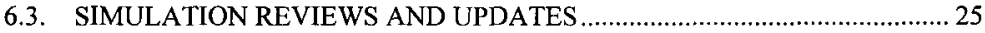

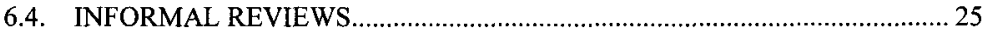

7.0 CONTROL AND VERIFICATION OF DESIGN CHANGES........................ 26

8.0 AS-BUILT TEST AND INSPECTION PLAN AND SCHEDULE ................... 27

8.1. FINAL CONSTRUCTION/EQUIPMENT INSTALLATION …....................... 27

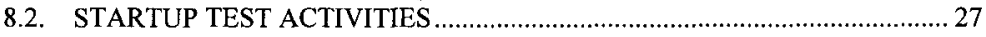

8.2 .1 FACTORY ACCEPTANCE TESTING ................................................... 27

8.2.2 CONSTRUCTION ACCEPTANCE TESTING (CAT) ……...................... 28

8.2.3 PREOPERATIONAL ACCEPTANCE TESTING .................................... 28

9.0 PROCESS VALIDATION DURING INITIAL OPERATION .......................... 28

9.1. BULK WATER REMOVAL RADIATION LEVELS ....................................... 29

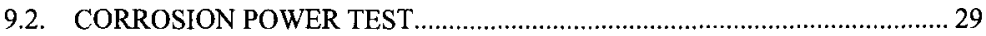

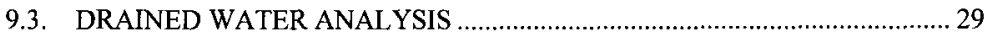

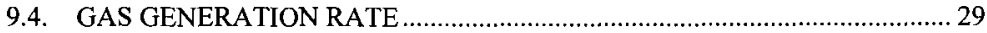




\subsection{INTRODUCTION AND BACKGROUND}

\subsection{PURPOSE AND SCOPE OF PLAN}

This Verification and Validation (V\&V) Plan defines current and planned design verification and validation activities to be performed in support of the Cold Vacuum Drying Facility. The purpose of the plan is to provide a verification/validation approach for closure for the CDVF definitive design phase and the path forward for CVD process and facility validation testing.

The requirements for V\&V planning and methodology are documented in Administrative Procedure 6-027-00, SNF Project Design Verification Requirements. This is a new administrative procedure which implements the Verification of Solution requirements contained in HNF-PRO-1819, PHMC Engineering Requirements, and the verification requirements of WHC-SD-SNF-SEMP-001, Spent Nuclear Fuel Project Systems Engineering Management Plan. This procedure replaces Spent Nuclear Fuels Engineering Practices, HNF-1613, Design Verification Requirements, EP-4.1.

Design of the CVD Facility is well established at this time. Therefore, this plan also summarizes V\&V activities that took place during previous design phases. Design basis documents and additional documents that define CDVF design requirements are identified in Section 2 of this plan.

This plan addresses V\&V activities associated with past (in summary only) and current phase(s) of the CVD Facility design, including: 1) project requirements definition, 2) conceptual design verification 3) definitive design verification to be performed as part of the Comprehensive Design Review, and 4) verification and validation activities which will be completed following the comprehensive design review, which consists primarily of testing. It also identifies past V\&V planning and activities and a means of assessing the adequacy of current and planned V\&V. Table 1 provides a detail of these activities in a graphical format that can be used to quickly review the status and completeness of CVD Facility validation and verification activities.

This plan is being prepared in conjunction with the CVD Facility Comprehensive Design Review. For the purposes of supporting the review, this plan serves three specific purposes: 1) it provides a summary and reference to past and present CVD validation and verification activities and documents; 2 ) it provides specific planning for the design review, based on the requirements of AP 6-027; and 3) it provides details of planned $V \& V$ activities. It also presents the documents that define CVD Facility requirements and acceptance criteria, and specifies verification methods used. 


\subsection{DESCRIPTION OF DESIGN VERIFICATION AND VALIDATION}

Design verification is a systems engineering process used to ensure:

- Design is technically adequate

- Design inputs have been evaluated and verified for their impact on the design (final and subsequent changes/revisions)

- Design meets the applicable requirements for environmental, quality, safety, and performance at a reasonable cost

- Operations requirements are met

$V \& V$ includes the complete set of activities that verifies that the end products meet the customer's needs, perform their specified functions, and meet requirements. V\&V methods include independent reviews, alternate calculations and simulations (generally conducted throughout the design process), informal review, formal design reviews, and inspection and testing activities performed during design, manufacturing, construction and turnover activities. The extent of verification and validation is generally based on the importance and complexity of the final design product. Verification consists of determining and documenting whether items, processes, and documents meet specified constraints and requirements. 


\section{SNF-4396, Rev. 0}

Verification is performed at each level of the technical baseline, from hardware item through the system level. Validation usually consists of comparing the results of analyses and simulations to measured results and showing that any differences were expected or within acceptable error. The use of design verification in the design and design change process is shown in flowchart form in Figure 1.

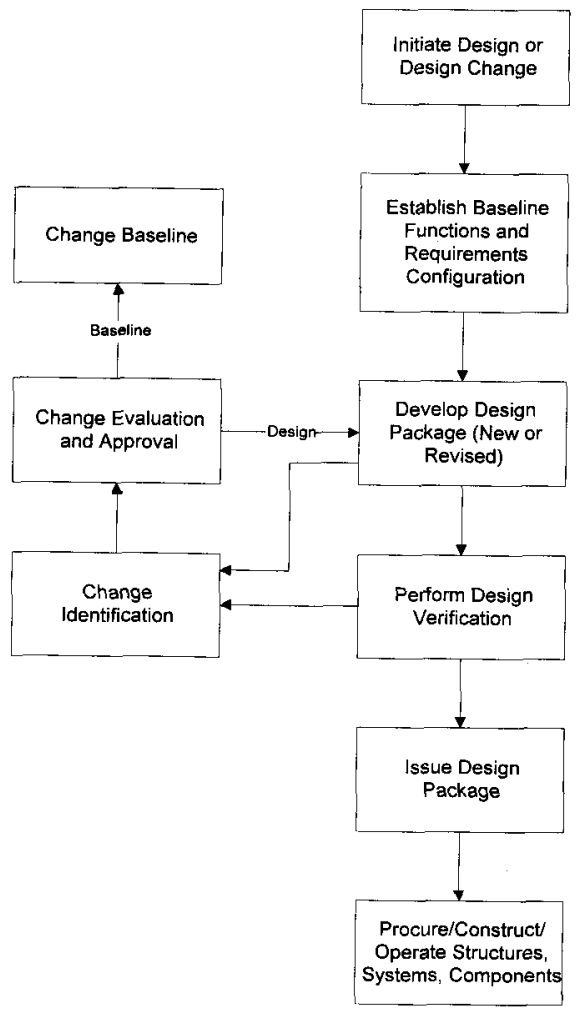

Figure 1. Design Verification in the SNF Design Process 


\subsection{PLAN REQUIREMENTS}

In accordance with AP 6-027, Verification and Validation planning should address a number of requirements. For this plan, requirements that have already been addressed during earlier phases of the project are outreferenced by the source documents that previously defined or met planning requirements. The following table summarizes plan requirements and outreferences planning documents for those items not specifically addressed at this phase of V\&V planning:

\begin{tabular}{|l|l|}
\hline $\begin{array}{l}\text { Applicable Planning and Verification } \\
\text { Requirement }\end{array}$ & Where addressed \\
\hline $\begin{array}{l}\text { Verification activities are required and planned for at } \\
\text { each project stage }\end{array}$ & Section 2.0 and Table 1 \\
\hline $\begin{array}{l}\text { Verification of acceptance criteria and requirements } \\
\text { included in general project planning. }\end{array}$ & Section 2.0 and Table 1 \\
\hline $\begin{array}{l}\text { Planning shall address each requirement, identifying } \\
\text { method and acceptance criteria, stage at which } \\
\text { performed. }\end{array}$ & $\begin{array}{l}\text { See documents listed in } \\
\text { Section } 2.0 . \text { and Table 1 }\end{array}$ \\
\hline $\begin{array}{l}\text { Planning documents shall include a method to control } \\
\text { and status verification. }\end{array}$ & $\begin{array}{l}\text { Section } 4.5,4.6, \text { and } 6.0, \text { and } \\
7.0\end{array}$ \\
\hline $\begin{array}{l}\text { Radiological design verification shall be addressed. } \\
\text { The documented field verification program shall } \\
\text { verify, by means of field inspection and design } \\
\text { verification, that the selected drawings describe the } \\
\text { actual hardware configuration of the structure, } \\
\text { system, or component. }\end{array}$ & Section $4.3,4.4,4.5 .2$ \\
\hline
\end{tabular}




\subsection{ORGANIZATION OF PLAN}

Verification and Validation activities are addressed by the design phase element. A summary of past activities is provided, however, emphasis is on the verification of the current definitive design phase. For activities associated with the definitive design phase, recent, current, and planned activities are presented, the particular method of verification and the details of how it was or will be performed is discussed.

The methods used at the current phase of the design include:

- Design verification of equipment and processes

- Design Reviews

- Calculations, Models, and Simulations

- Testing/Inspection

- Construction and Equipment Installation

- Construction Testing

- Process Validation

References are provided for each system and includes planning documents and documentation of the $\mathrm{V} \& \mathrm{~V}$ activities, such as test reports, design review reports, process simulations, and calculations. Table 1 provides a summary of all $V \& V$ activities addressed in this plan, including document numbers, titles, and plan dates for activities not yet performed.

Detailed planning for the CVD Facility Comprehensive Design Review is presented in Section 4.0.

\subsection{SUMMARY OF REQUIREMENTS AND VERIFICATION DOCUMENTS BY PROJECT PHASE}

This section summarizes requirements and verification documentation for all project phases. Acceptance criteria and requirements for the CVD Facility project are established in documents associated with various project and design phases. (Refer to SNF-4248 Cold Vacuum Drying Facility Document Hierarchy Definition Document for a detailed description of these documents.) 


\subsection{CONCEPTUAL DESIGN PHASE}

The SNF Project-level Functional Requirements Baseline describes the SNF Project approach, top-level requirements and constraints, and top-level functional and architectural features. This baseline provides the necessary details for start of a sub-project conceptual design. The following documents are the SNF Project Functional Baseline Documents applicable to the CVD Facility.

- HNF-SD-SNF-TI-015, Spent Nuclear Fuel Project Technical Databook

- HNF-SD-SNF-OCD-001, Spent Nuclear Fuel Project Product Specification

- HNF-SD-SNF-RPT-011, Spent Nuclear Fuel Project Design Basis Capacity Study

- H-2-825868, SNF Project Level 0 Process Flow Diagram

- HNF-SD-SNF-DB-003, Spent Nuclear Fuel Path Forward Additional NRC Requirements

- WHC-SD-SNF-FRD-020, K Basin SNF Cold Vacuum Drying Facility Functions and Requirements

Verification activities associated with the CVD conceptual design phase are documented in WHC-SD-SNF-CDR-003, Cold Vacuum Drying System Conceptual Design Report and HNF-SD-SNF-TRP-021, Hanford Spent Nuclear Fuel Cold Vacuum Drying Proof of Concept Test Report

\subsection{PRELIMINARY DESIGN PHASE}

The Performance Requirements Baseline documents the basis for initiating and the requirements for verifying the CVD preliminary design. These are:

- WHC-SD-SNF-TP-018, Hanford Spent Nuclear Fuel Cold Vacuum Drying Test Specification and Test Plan

- WHC-SD-SNF-TC-008, Hanford Spent Nuclear Fuel Vacuum Drying Test Procedure

- HNF-SD-SNF-TRP-021, Hanford Spent Nuclear Fuel Cold Vacuum Drying Proof of Concept Test Report

- WHC-SD-SNF-CDR-003, Cold Vacuum Drying System Conceptual Design Report

- WHC-SD-SNF-PSE-003, Preliminary Safety Evaluation for the Spent Nuclear Fuel Project Cold Vacuum Drying System

- WHC-SD-SNF-DB-010, Cold Vacuum Drying System Natural Phenomena Hazards

At present, the CVD Facility Safety Class Instrumentation and Control System is at the Preliminary Design Phase. Current verification activities are documented in Section 3.0 of this plan. The requirements for this system are documented in:

- Performance Specification for Safety Class Instrumentation and Control 


\subsection{DEFINITIVE DESIGN PHASE}

The Design Requirements Baseline provides the requirement basis for the definitive design. The following documents are considered the design requirements baseline documents for the CVD Project.

- HNF-SD-SNF-RD-001, SNF K Basins and CVDF Standards and Requirements Identification Documents

- H-1-81166, SNF Project K Basin SNF Vacuum Drying Level I PFD

- HNF-SD-SNF-DRD-002, Cold Vacuum Drying Facility Design Requirements Document

- Interface Control Documents

Testing and associated acceptance criteria associated with the definitive design phase are found in HNF-SD-SNF-TP-036, SNF Cold Vacuum Drying Test Specification and Test Plan.

The Design Configuration Baseline shows the progress of the CVD in refining the design and developing the "build to" design packages. It includes the engineering design media that must be verified as part of the definitive design phase. This includes:

- System Design Descriptions (includes 29 system documents)

- W-441-C1, Construction Specification (includes facility drawings)

- Procurement Specifications W-441-P1 through P5 (includes equipment drawings)

- SNF-3001, Spent Nuclear Fuel Project Cold Vacuum Drying Facility Calculation Database

- SNF-4148, Spent Nuclear Fuel Project Cold Vacuum Drying Facility Master Equipment List

- HNF-SD-SNF-SEL-002, Spent Nuclear Fuel Project Cold Vacuum Drying Facility Safety Equipment List.

- HNF-3342, Hanford Spent Nuclear Fuel Cold Vacuum Drying First Article Initial Test Finding Report

- HNF-SD-SNF-SAR-002, Spent Nuclear Fuel Project Cold Vacuum Drying Facility Safety Analysis Report

A summary of completed verification activities associated with this design phase are reviewed in Section 3.2.

This plan specifically addresses current verification activities associated with the definitive design package. The verification activity addressed in detail in Section 4 of this plan is the CVD Comprehensive Design Review. 


\subsection{CALCULATIONS AND SIMULATIONS}

A detailed listing of all calculations performed to date in support of CVD Facility can be found in the Calculation Index (SNF-3001). Calculations have been organized in the index into categories listed below. Table 1 of this plan provides cross-referencing of individual analyses to various CVD Facility equipment and facility subsystems.

- Safety/SAR Reports \& Calculations

- Criticality, Shielding, Radiation and ALARA Analyses

- Civil Reports \& Calculations

- Structural Reports \& Calculations

- Seismic Reports \& Analyses

- Facility Throughput Analysis

- CVD Process Reports \& Calculations

- VPS and TW System Reports \& Calculations

- PWC System Reports \& Calculations

- Electrical Power Reports \& Calculations

- HVAC/Ref. Air/Stack Monitoring Reports \& Calculations

- SCIC Reports \& Calculations

- I\&C Reports \& Calculations

- Mechanical Utilities Reports \& Calculations

- Fire Hazard Analysis/Fire Protection

- SNF Supporting Reports \& Calculations (MCO/Cask \& Contents)

- SNF Data and Characterization Reports \& Calculations

\subsection{SUMMARY OF COMPLETED DESIGN VERIFICATION ACTIVITIES}

This section discusses V\&V that was performed during conceptual, preliminary and definitive design phases of the project. Figure 2 presents a summary timeline for CVD V\&V activities, and includes completed and planned activities.

\subsection{CONCEPTUAL AND PRELIMINARY DESIGN ACTIVITIES}

This section summarizes several completed verification activities associated with the CVD Facility conceptual and preliminary design phase. Documentation of additional activities is found in Table 1 .

\subsubsection{FORMAL DESIGN REVIEWS}

The conceptual design was documented and reviewed in a May 96 design report, Cold Vacuum Drying System Conceptual Design Report, WHC-SD-SNF-CDR-003, Rev. 0. Design reviews were conducted at $30 \%$ and $90 \%$ preliminary design completion points. These were conducted in July and September 1996 and are documented in A/E design reports. 


\subsubsection{TESTING}

\subsubsection{PROOF OF CONCEPT TESTING}

A proof of concept test program was initiated in April 1996. The primary objective of these tests was to help determine the performance of the CVD process using a one-fit size MCO containing mock fuel, sludge, or scrap. Other objectives included determining equipment performance, heating cycles, and approximate water retention amounts on MCO baskets full of mock fuel or scrap. The results of this testing validated the feasibility of drying an $\mathrm{MCO}$ within the proposed time period. The results of these tests are documented in HNF-SD-SNF-TRP-021, Hanford Spent Nuclear Fuel Cold Vacuum Drying Proof of Concept Test Report, August 1997.

\subsubsection{HOT TESTING}

Uranium oxidation rate data was collected on small samples from two stored N-Reactor spent fuel elements and in hot cell and shipping studies. Uranium oxidation rates under the varying conditions found in the $\mathrm{MCO}$ are important in modeling heat generation, gas composition, and particulate generation in the MCO. These rates are used in SNF Project safety basis calculations. Oxidation rate data was collected for tests in moist air, dry air, and moist helium. These tests were performed to validate and correlate data documented in the SNF Project Technical Databook that was used in the project design basis. Assessments were made of all reaction rate data and documented (Pajunen, 1999) and an independent peer review was provided (Fauske and Associates). Specific test references are provided below:

- HNF-4206, Oxidation Kinetics of K-Basin Fuel, Trimble, March 1999.

- Hot cell studies that dried N-Reactor fuel elements in moist inert gas, Lawrence, 1998.

- Fuel element shipping observations at $20^{\circ} \mathrm{C}$, measuring gas generation rates, Briggs and Roe, 1997.

The results of these tests are summarized in the following documents:

- HNF-4165, Uranium Oxide Rate Summary for the Spent Nuclear Fuel Project, Pajunen, March, 1999.

- SNF-4238, Uranium Oxidation Rates Issue Closure Package, Sexton, March 1999.

\subsection{DEFINITIVE DESIGN VERIFICATION ACTIVITIES}

This section summarizes those recently completed verification activities associated with the CVD Facility definitive design phase.

\subsubsection{FORMAL DESIGN REVIEWS}

The sections below describe CVD Facility design reviews that have been conducted to date. These formal design reviews were consistent with the previous design review guiding document, HNF-PRO-445, Design Verification Requirements. 


\subsubsection{CVD FACILITY HOOD AND PROCESS PIPING ASSEMBLY}

A formal design review was completed for the Process Hood and Piping Assembly Procurement Specification (W-441-P4, Rev. 0). Design review completion was based on Revision 3 of the Design Requirements Document and Revision 3 of the Safety Equipment List. The design review committee closed the formal design review on October 1, 1998.

\subsubsection{SAFETY CLASS HELIUM SYSTEM (SCHE)}

A formal design review was completed for the Safety Class Helium System Procurement Specification (W-441-P5, Rev. 0). Design review completion was based on Revision 3 of the Design Requirements Document and Revision 3 of the Safety Equipment List. The design review committee closed the formal design review on October 1, 1998.

\subsubsection{PROCESS WATER CONDITIONING SYSTEM (PWC) (SNF-3082)}

A formal design review consistent with HNF-PRO-445, Design Verification Requirements, was completed for the Cold Vacuum Drying Facility Process Water Conditioning System Procurement Specification (W-441-P2, Rev. 0) in September 98. Design review completion was based on Revision 3 of the Design Requirements Document and Revision 3 of the Safety Equipment List. Currently, all RCRs have been closed, and the release of the design review closure package is pending.

\subsubsection{INSTALLATION DESIGN REVIEW}

Formal design review of the equipment installation and installation drawing package was held in January 1999. Currently, all RCRs have been closed, and the release of the design review closure package is pending.

\subsubsection{TESTING}

The CVD first article testing program described below was conducted in the Hanford 300 Area 306E building through March 1999. Test planning, procedures and acceptance criteria were provided in HNF-2402, Hanford Spent Nuclear Fuel Cold Vacuum Drying Proof of Performance Test Procedure and HNF-SD-SNF-TP-036, Hanford Spent Nuclear Fucl Cold Vacuum Drying Proof of Performance Test Specification and Test Plan.

First article testing was conducted in two phases; initial functional and performance testing, and process optimization testing. Initial test finding are documented in HNF3342, SNF Cold Vacuum Drying First Article Initial Test Finding Report, Oct 198 . More recent optimization test results are documented in HNF-4057, Cold Vacuum Drying Proof of Performance (First Article Testing) Test Results. Detailed information regarding test setup, objectives, results, and recommendations are found in each report. 


\subsubsection{INITIAL FIRST ARTICLE TESTING}

Initial first article testing served to validate and verify the functional performance of the Process Equipment Skid (PES), which includes the Vacuum Purge System (VPS) and Tempered Water System (TWS). The tested system was a first article unit built to Procurement Specification W-441-P2 Rev N. The testing also verified the performance capabilities of a prototype process ventilation hood/seal ring assembly, piping, a first generation monitoring and control system (MCS), a portion of the $\mathrm{PWC}$, and a prototype of the safety class helium system. The test plan under which testing was conducted (HNF-SD-SNF-TP-036) described process parameters such as water retention amounts, establishment of the vacuum process, and drying times as data to be gathered during the testing process. Additional feature tests included checking and verifying the performance of specific hardware such as the vacuum pump, condenser/chiller, MCO ports and process connectors, ventilation hood, seal ring, and system piping and valving. A discussion of detailed findings can be found in HNF-3342, Section 5.0, Test Findings, and 6.1, Feature Test Results.

\subsubsection{PHASE II FIRST ARTICLE TESTING}

During this phase of first article testing, tests were conducted to determine MCO drying times, equipment reliability, and control system performance. While determining the Multi-Canister Overpack (MCO) drying times, equipment reliability issues and the control system operation problems were identified and solutions provided. HNF-4057, Cold Vacuum Drying Proof of Performance (First Article Testing) Test Results, provides results from the process tests, and details programming and hardware changes made during the testing.

\subsubsection{CALCULATIONS AND SIMULATIONS REVIEW}

The Calculation Index (SNF-3001) identifies all calculations and simulations that have been performed in support of CVD. It identifies by date and title recent revisions to calculations and simulations required to incorporate design changes and findings from the test program. Current verification activity associated with these calculations and simulations are discussed in Sections 6.2 and 6.3.

\subsection{COMPREHENSIVE CVD FACILITY FORMAL DESIGN REVIEW}

\subsection{PURPOSE}

The CVD Facility Comprehensive Design Review will serve as a key element of CVD Facility definitive design verification and assist in CVD Facility design closeout. A design report prepared in support of this review, SNF-4257, defines and provides the complete set of engineering design media which are the subject of the review, as well as the set of engineering requirements and supporting documents which will further assist reviewers in conducting design verification. These documents are identified in Section 4.4. 


\section{SNF-4396, Rev. 0}

\subsection{SCOPE AND LIMITATIONS OF REVIEW}

This review will focus on design media verification. The scope of the review begins with identifying the appropriate set of criteria documents for the design to be reviewed against. It will identify all pertinent design output documents that must be reviewed against the criteria.

The review is intended to verify current CVD design media by determining if: 1) the design completely and accurately reflects design functions and requirements, and 2) the design documents are consistent with each other, and 3) the design media accurately reflects the current design. The principal design criteria document used in the review will be HNF-SD-SNF-DRD-002, Rev 4, CVD Design Requirements Document.

The scope of the review can also be bounded by the considering systems that have been verified and validated in the First Article Test program. For those portions of the design which have been verified through first article testing, the formal design review need not consider adequacy of the design. The formal review will assess those areas to determine if the testing which has been done or which is planned is adequate to validate the design.

The review will use a graded approach to look at the overall design in moderate depth, and select specific areas to review in depth. These areas will be chosen based on the following priorities:

- Safety class systems and equipment.

- Systems identified in the critical design parameters section of this plan (Section 5).

- Systems selected by the team in the first week of review

The design review will focus on four important issues relative to the specific documents being reviewed, which are completely defined in Section 4.4 below:

- Adequacy of the design to meet the design criteria as specified in HNF-SD-SNFDRD-002 Design Requirements Document

- Consistency of the System Design Descriptions with the Final Safety Analysis Report

- Consistency of the design documentation with the Final Safety Analysis Report

- Consistency of the System Design Descriptions with the design documentation

The scope of the review will be limited to these four points.

The FSAR will also be reviewed for content and understandability by the safety reviewer. 


\subsection{DESIGN REVIEW COMMITTEE}

The formal design review team will consist of the following positions and team members, selected in accordance with the requirements of AP-027-00. Each independent reviewer has expertise in a particular discipline determined necessary based on the content of the review.

\begin{tabular}{|l|l|l|}
\hline Review Team Role & Name of Reviewer & Company \\
\hline $\begin{array}{l}\text { Review } \\
\text { Chairman/Mechanical }\end{array}$ & George Crawford & ESG, LLC \\
\hline Recorder/Mechanical & Steve Riesenweber & ARES \\
\hline Mechanical & Dave Bennett & Oceaneering \\
\hline Electrical (I\&C) & Dave Clark & PNNL \\
\hline Chemical / Process & Jim Nelson & LMHC/Vista Research \\
\hline Chemical / Process & Luc De Lamartinie & NUMATEC \\
\hline Structural & Vern Severud & \\
\hline $\begin{array}{l}\text { Configuration } \\
\text { Management/Power } \\
\text { Electrical }\end{array}$ & Ted Moleff & ARES \\
\hline Quality Assurance & & \\
\hline Safety & Jack McGee & COGEMA \\
\hline Operations & Lewis Muhlestein & ARES \\
\hline Operations & John Gregory & DESH \\
\hline Administrative Support & Walt Alaconis & DESH \\
\hline Department of Energy & Bisa Inman & ARES \\
\hline Department of Energy & Saleem Farooqui & DOE \\
\hline
\end{tabular}

\subsection{DOCUMENTS SUB.JECT TO REVIEW}

The following documents will be subject to review, except where the document is supplied for the reference or supporting documentation only.

\begin{tabular}{|l|}
\hline Design Documents Subject to Review \\
\hline Design Requirements Document, Rev. 4 (DRD), HNF-SD-SNF-DRD-002 \\
\hline System Design Descriptions \\
\hline SNF-3060, Radiation Monitoring (RM) and Room Air Quality (AQ) \\
\hline SNF-3061, Civil/Structural Systems (CIV) \\
\hline SNF-3062, Vacuum Purge System (VPS) \\
\hline SNF-3063, Residual Gas Monitoring System (RGM) \\
\hline SNF-3064, Helium MSLD and Auxiliary Vacuum (MSLD) \\
\hline
\end{tabular}


SNF-4396, Rev. 0

SNF-3065, Communication Systems (COMM)

SNF-3066, Compressed Air System (CA/CI)

SNF-3067, General Service Helium System (He)

SNF-3068, Safety Class Helium (SCHe)

SNF-3072, Cranes and Hoists (HOI)

SNF-3073, Effluent Drains System (EFS)

SNF-3074, Condensate Collection System (CCS)

SNF-3075, Electrical Systems (ES)

SNF-3076, Specialty Equipment and Tools

SNF-3077, Service Water System (SWS) and Fire Protection System (FP)

SNF-3078, De-ionized Water System (DI)

SNF-3079, Potable Water System (PW)

SNF-3080, Sewage Collection System (SANS)

SNF-3081, HVAC Systems (HVAC)

SNF-3082, Process Water Conditioning System (PWC)

SNF-3083, Conditioned Water Shipping System (SWS)

SNF-3084, Contaminated Water Sampling and Analysis System (SMP)

SNF-3085, Tempered Water/Tempered Water Cooling (TW/TWC)

SNF-3086, Chilled Water System (CW)

SNF-3087, Vacuum and Purge System Chilled Water (VPSCHW)

SNF-3088, Stack Monitoring System (SM)

SNF-3089, Security System (SEC)

SNF-3090, Monitoring and Control System (MCS)

SNF-3091, Safety Class Instrumentation and Control (SCIC)

CVD Facility Engineering Drawings

Drawing Tree

Engineering Flow Diagrams

Facility Drawings

Equipment Drawings

Installation Drawings

Final Safety Analysis Report (FSAR), DRAFT

Equipment Procurement Specifications

W-441-P1, Process Equipment Skid Procurement Specification

W-441-P2, Process Water Conditioning Skid Procurement Specification

W-441-P3, Monitoring and Control System Procurement Specification 


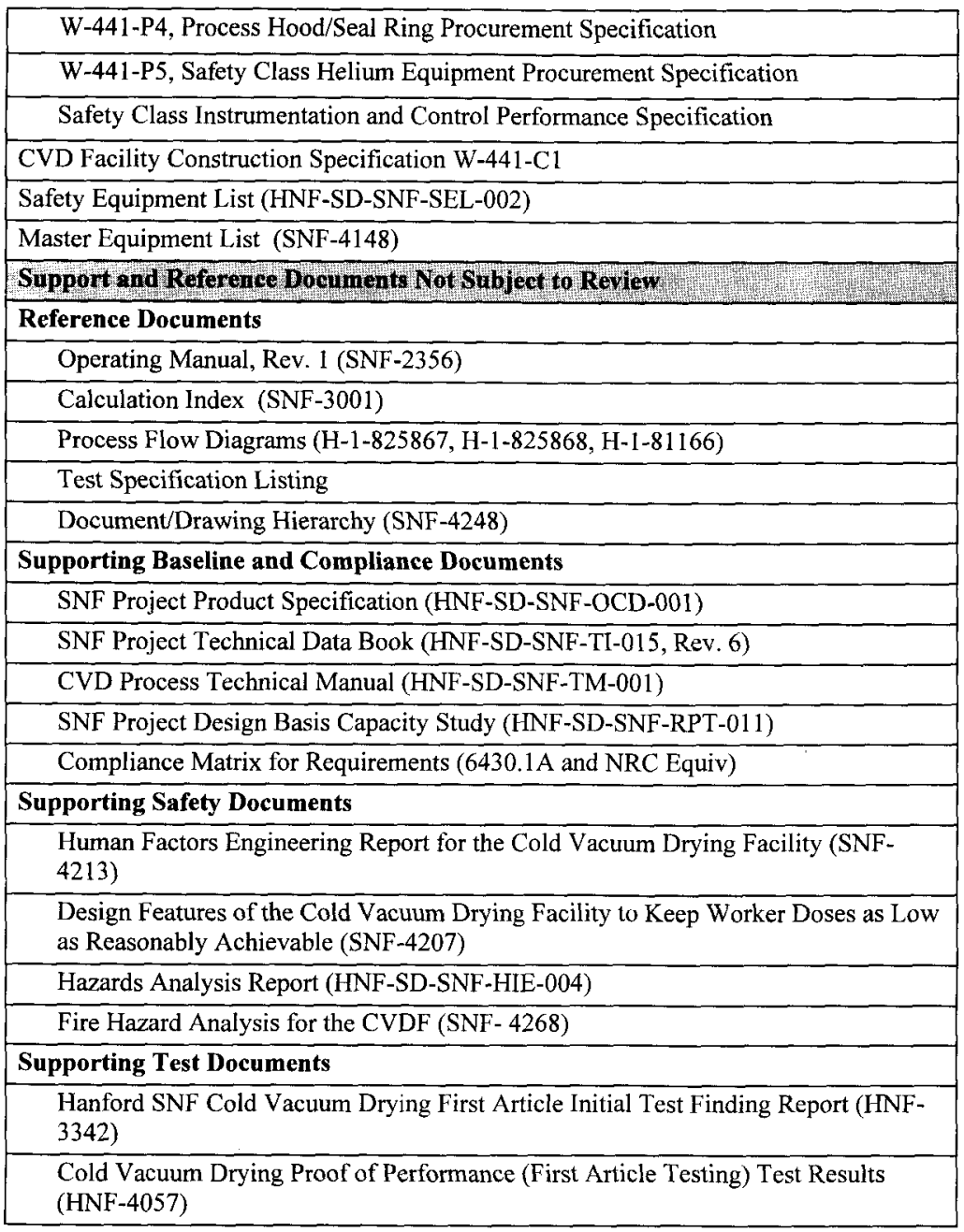

4.5. 


\subsection{REVIEW PROCESS AND GUIDELINES}

\subsubsection{DESIGN REVIEW BRIEFING}

An initial design review briefing will be held on April 12, 1999. Presentations and information provided to the reviewers will be consistent with requirements identified in AP-027-00 (5.5.4.1) It will include presentations by design authorities, project manager, and review committee chairman, and required documents will be provided. An agenda, the schedule for review meetings, and specific assignments will also be presented. All review documents listed in Section 4.4 will be made available to reviewers at the time of the briefing.

\subsubsection{DESIGN REVIEW CHECKLIST}

To guide the design review process, the general checklist which is an appendix to HNFPRO-1819, PHMC Engineering Requirements and Administrative Procedure AP-6-027, Design Verification Requirements was modified and is attached in Appendix A. This checklist will be used to guide the reviewers in their assigned areas. A separate checklist will be completed by each reviewer for each document reviewed. They will be included in the design review report as an appendix.

\subsubsection{REVIEW AND COMMENT METHODOLOGY}

All comments will be aimed at significant design performance parameters. Design preference comments will not be included in the review process or the design report.

Only substantive comments or questions will be raised and tracked through the database.

Issues that are considered minor, but worth tracking, will be provided in a list to the project management team, but will not be included for comment disposition by RCR.

When all comments have been completed, they will be consolidated into a single set of RCRs. Any conflicting or diverging comments will be resolved within the design review team prior to transmittal. All comments will represent the consensus position of the review team. Comments will be submitted using the RCR form shown in Appendix B.

The CVD project team will prepare written dispositions for the comments. The review team will review the dispositions and negotiate final wording and concurrence with the comments and the dispositions.

Finally, when all comments have been dispositioned and agreed upon, the review team will meet with the project management staff to agree on the disposition and action item list, prior to issuing the final design report. 


\subsection{DESIGN REVIEW REPORT AND CLOSEOUT}

A design review report issued by the Design Review Committee secretary will be issued following completion of the final design review meeting at the close of the review period. Design review report format and content will be per guidance provided by AP-027-00, Appendix B.

When the design review report has open action items, a design review completion report will be prepared and issued at the completion of design by the design authority after all action items are resolved.

\subsection{CRITICAL DESIGN PARAMETER VERIFICATION}

This section of the design report presents an overview of the critical parameters of the CVD process based on findings from analyses and testing. This provides guidance for focus of the Comprehensive Design Review discussed above. In accordance with AP$027-00$, the extent of design verification required for a particular design is governed the importance to safety, the environment, complexity of the design, degree of standardization, state of the art, similarity with previously proven designs, and programmatic impacts.. These critical parameters below have been identified as those critical to safety and process completion, and therefore requiring particular focus during design verification. In the discussion below, process findings are presented, along with appropriate document references to how and when verification and validation of these critical parameters took place. The complete document references are found at the end of this section.

\subsection{DRYNESS}

The purpose of the CVD Process is to remove free water from the MCO. The project's safety basis relies, in part, on the free water remaining in the $\mathrm{MCO}$ being no greater than $200 \mathrm{~g}$ (Pajunen, 1998a). This is assured by a Proof of Dryness Demonstration (Pajunen, 1998b) step, in which pressure is held to less than 8 torr for a specified time period (depending on the number of scrap baskets in the $\mathrm{MCO}$ ).

\subsection{CYCLE TIME}

Analysis of the SNF Project's Design Basis Capacity (Cleveland and Pajunen, 1999) has used a 72-hour cycle time from the time an MCO enters the facility until it leaves and the same bay is ready to receive another one. Less than haif of this cycle time is associated with the drying cycle. The CVD Facility will be processing MCOs from only the K-West basin for approximately one year, both basins for approximately one year, and only the $\mathrm{K}$-East basin for one year. It is only during the second year that the CVD Facility will be operating at maximum throughput.

Although the sum of critical path times currently in the Operations Manual (Irwin, et. al., 1999) totals more that 72 hours, the actual mean cycle time is expected to be less than 72 hours. The major steps in the process and the critical path times associated with them in Irwin, et. al., 1999, are as follows: 
SNF-4396, Rev. 0

Table 2. Critical Path Times Associated with Major Steps in CVD Process

\begin{tabular}{|l|l|l|}
\hline $\begin{array}{l}\text { Ops Manual Process } \\
\text { Step }\end{array}$ & Process Reference & Critical Path Time \\
\hline Hook-up & (steps 1 through 23e) & 7 hours, 15 minutes \\
\hline Heat-up & (steps 23f through 24) & 5 hours, 34 minutes \\
\hline Drain & (steps 25 through 26) & 2 hours, 13 minutes \\
\hline Dry & (steps 27 through 40) & 25 hours, 51 minutes \\
\hline Proof Test & (steps 41 and 42) & 21 hours, 21 minutes \\
\hline Cooldown & (step 43) & 6 hours \\
\hline Disconnect/Decon & (steps 44 through 67) & 6 hours, 25 minutes \\
\hline \multicolumn{2}{|r}{ TOTAL CRITICAL PATH TIME } & 74 hours, 39 minutes \\
\hline
\end{tabular}

\subsection{SAFETY BASIS PARAMETERS AFFECTING CVD OPERATIONS}

The safety basis of the CVD process requires prevention of three key accidents: thermal runaway reaction, $\mathrm{MCO}$ internal explosion, and MCO external explosion. Criticality control is also a requirement that impacts process design.

\subsubsection{THERMAL RUNAWAY REACTION}

Thermal stability in the MCO is based on the fact that a helium filled MCO at atmospheric pressure is inherently stable, regardless of water inventory in the MCO, provided temperature control of the annulus between the MCO and the cask is maintained (Duncan and Plys, 1998). The heatup that can occur during vacuum operations is so slow that an initial vacuum cycle of 8 hours can be done with full confidence of a broad safety margin in a bounding MCO. Since the helium filled MCO is inherently stable, it has been shown that an indefinite sequence of 4 hours of helium purge at atmospheric pressure and 4 hours of vacuum pumping will maintain acceptable MCO temperatures regardless of the amount of water present in the $\mathrm{MCO}$.

Therefore the safety basis of the Cold Vacuum Drying process requires:

- Adherence to the 8-4-4 cycle,

- The presence of tempered water in the annulus to a height equal to the top of the fuel, and

- Assurance that the tempered water will not be heated above a $50 \mathrm{C}$, based on safety basis calculations. This is provided by imposing a setpoint of $46.9 \mathrm{C}$ with an allowance for instrument uncertainty of 3.1 C. (Whitehurst, 1999)

Termination of the 8-4-4 cycle relies on the pressure rebound test to demonstrate that the MCO is dry. The pressure rebound test requires that an MCO held below 10 torr does not rise in pressure more than 2.4 torr during a one-hour test (Pajunen, 1998b). 


\subsubsection{MCO INTERNAL EXPLOSION}

Maintaining the MCO below lower flammability limits relies on the following strategies:

- For pre-drying conditions, the $\mathrm{MCO}$ is maintained at above atmospheric conditions to preclude the possibility of air in-leakage.

- During drying, hydrogen concentration is limited by maintaining a helium purge. The required purge rate is based on a safety basis calculation of $1.4 \mathrm{scfm}$ and an allowance for instrument accuracy (Whitehurst, 1999).

- When sufficient vacuum is established to demonstrate that flammability is impossible, purge is no longer required. A requirement of 10 torr is based on a calculation (Pajunen, 1999) of 12 torr and 2 torr instrument uncertainty (Whitehurst, 1999). The purge may be turned off for 5 minutes to establish the vacuum. If the 10 torr vacuum cannot be established, the purge must be restarted for an hour.

Prior to installation of the MCO welded cover cap at the CSB, the MCO depends on the shield plug's mechanical seals to provide radiological confinement, limit hydrogen releases and prevent air ingress. These consist of the main shield plug seal ring and four shield plug port cover gaskets. The CVD Facility will leak test the MCO's top closure seals prior to releasing it for shipment to the CSB. The leak test must demonstrate that the total integrated leak rate past the MCO's top closure seals does not exceed $1 \times 10^{-5}$ std $\mathrm{cc} / \mathrm{s}$ (Sherrell, 1999).

\subsubsection{MCO EXTERNAL EXPLOSION}

The Process Water Conditioning receiving tanks are given a pre-purge and post-purge with helium to reduce hydrogen concentration in the tank. A safety basis calculation requires a purge of 19 minutes at $8.0 \mathrm{scfm}$. The setpoint is $8.4 \mathrm{scfm}$ to allow for instrument uncertainty (Whitehurst, 1999).

Design recommendations associated with hydrogen control external to the $\mathrm{MCO}$ will be summarized in a pending report (Miska, 1999).

\subsubsection{CRITICALITY CONTROL}

Criticality control at the CVD Facility is achieved by assuring that all vessels that potentially receive fissile material have critically safe geometries. For the PWC system, the receiving vessels are verified to have an inside diameter of less than 21.5 inches (Roblyer, 1998). 


\subsection{EFFICIENCY PARAMETERS}

\subsubsection{BASE PRESSURE}

The base pressure (the pressure at which the pressure rebound test is initiated) will influence operating efficiency. The lower the base pressure, the longer vacuum operations will be required to establish it. The higher the base pressure, the higher the probability of failing the pressure rebound test, requiring further drying.

The pressure rise criterion is 2.4 torr/hour, conducted at any pressure below 10 torr (Pajunen, 1998b). Therefore, the technical basis of the pressure rise test will allow a base up to 7.6 torr (allowing for a pressure rise of 2.4 torr to a resulting pressure no more than 10 torr).

The current requirement is to achieve a base pressure of 0.5 torr. Based on 306 testing, relatively little time is expected to transition from 7 torr to 0.5 torr.

\subsubsection{OPERATING TEMPERATURE}

Higher CVD operating temperatures will result in shorter drying times. However, the safety basis requires that the tempered water inlet temperature be kept below $50 \mathrm{C}$ (Duncan and Plys, 1998). The safety trip setpoint will allow for instrument inaccuracy, to assure the tempered water does not exceed $50 \mathrm{C}$ at the inlet. This setpoint is $46.9 \mathrm{C}$. The calculated uncertainty of the inlet temperature (Philipp, 1999), based on instrument data, is $3.1 \mathrm{C}$. The operating setpoint is set as high as possible while precluding false trips due to normal fluctuation. A setpoint of $46 \mathrm{C}$ is proposed, but will be lowered if false safety trips occur during facility testing. The setpoint should not be required to be lower than $45 \mathrm{C}$.

\subsubsection{PARTICULATE GENERATION AND CARRYOVER TO THE PWC IXM}

Particulate generated in the MCO and carried over in bulk water removal will be collected in the ion exchange modules (IXM). Sloughter, 1998, estimates that the nominal $\mathrm{MCO}$ will generate 75 grams of UO2 particulate prior to draining, and assumes that all of this will be carried over in bulk water removal. This equates to approximately $0.026 \mathrm{Ci}$ TRU/MCO. IXMs must be monitored and changed prior to accumulating enough particulate to be classified as TRU waste. The actual quantity of particulate removed by the IXM will determine the number of IXMs to be used at the CVD Facility. This will be determined by sampling the inlet and outlet of the IXM. UO2 accumulation in the IXM will be administratively limited to about $60 \mathrm{nCi} / \mathrm{gm}$ or $1.14 \mathrm{Ci}$ of UO2 per IXM. At $0.026 \mathrm{Ci} / \mathrm{MCO}, 400 \mathrm{MCO}$ would require approximately $10 \mathrm{IXMs}$. 


\section{SNF-4396, Rev. 0}

\subsection{DOCUMENT SOURCES FOR CRITICAL DESIGN PARAMETER DEFINITION}

Cleveland, K. J., and A. L. Pajunen, 1999, Spent Nuclear Fuel Project Design Basis Capacity Study, HNF-SD-SNF-RPT-011, Rev. 1A, Fluor Daniel Northwest, Richland, WA

Cowan, R. G., D. E. Ball, and W. C. Alaconis, SNF Process Validation Requirements, HNF-SD-SNF-CN-027, Rev. 0, DE\&S Hanford, Richland, WA

Duncan, D. R. and M. G. Plys, 1998, Simulation of Normal and Off-Normal MultiCanister Overpack Behavior, HNF-2256, Rev. 2, DE\&S Hanford, Richland, WA

Irwin, J. J., C. C. Pitkoff, and R. Whitehurst, 1998, Cold Vacuum Drying Facility Design Requirements Document, HNF-SD-SNF-DRD-002, Rev. 3a, Numatec Hanford Corporation and DE\&S Hanford, Richland, WA

Irwin, J. J., et. al, 1999, Spent Nuclear Fuel Project Cold Vacuum Drying Facility Operations Manual, SNF-2356, Rev. 1, Numatec Hanford Corporation and DE\&S Hanford, Richland, WA

McCracken, K. J., B. A. Crea, and B. C. Fryer, 1999, Cold Vacuum Drying Proof of Performance (First Article Testing) Test Results, HNF-(TBD), Draft, DE\&S Hanford, Richland, WA

Miska, C. R., 1999, CVD External Hydrogen Management Evaluation, SNF-4023, Rev 0, Numatec Hanford Corporation, Richland, WA

Pajunen, A. L., 1998a, Cold Vacuum Drying Residual Free Water Removal Test Issue Closure Package, HNF-2882, Rev. 0, COGEMA Engineering Corporation, Richland, WA

Pajunen, A. L., 1998b, Cold Vacuum Drying Residual Free Water Test Description, HNF-185l, Rev. 2, COGEMA Engineering Corporation, Richland, WA

Pajunen, A. L., 1999, Cold Vacuum Drying Process Technical Mamual, HNF-SD-SNFTM-001, Rev. 1 (Draft), DE\&S Hanford, Richland, WA

Philipp, B. L., 1999, CVD Setpoint Calculations, HNF-(TBD), Draft, COGEMA Engineering Corporation, Richland, WA

Piepho, M. G., and R. D. Crowe, 1998, Thermal Analysis of Cold Vacuum Drying of Spent Nuclear Fuel, HNF-SD-SNF-CN-023, Rev. 1, DE\&S Hanford, Inc., Richland, WA 
Roblyer, S. D., 1998, Criticality Safety Evaluation Report for the Cold Vacuum Drying Facility's Process Water Handling System, HNF-SD-SNF-CSER-006, Rev. 0, Fluor Daniel Northwest, Richland, WA

Sherrell, D. L., 1999, MCO Combustible Gas Management Leak Test Acceptance Criteria, HNF-2155, Rev. 1, DE\&S Hanford, Richland, WA

Whitehurst, R., 1999, Cold Vacuum Drying Facility Safety Class Instrument and Control System Design Description, SNF-3091, (Draft), Numatec Hanford Corporation and DE\&S Hanford, Richland, WA

Sloughter, J. P., 1998, Estimates of Particulate Mass in Multi-Canister Overpacks, HNF1527, Rev. 2, Numatec Hanford Corporation, Richland, WA

\subsection{OTHER CURRENT CVD FACILITY VERIFICATION}

\subsection{SCIC PRELIMINARY DESIGN REVIEW}

A redesign of the Safety Class Instrumentation and Control System (SCIC) is currently underway. The first design review, which focuses primarily on hardware design, was conducted on 29 March 1999. A second review planned for April 99, will be conducted to verify and validate software and control systems. This review is being conducted by the SCIC design agent for the CVD project organization. The reviews will be conducted and results documented using guidance from AP-027-00.

\subsection{CALCULATION VALIDATION AND REVIEW}

An independent validation of selected calculations is currently being performed by $F$. Heard of Numatec Hanford. This review focuses primarily on CVD design calculations that have not yet been validated or verified by testing. Secondarily, the review is focusing on calculations performed in the past that may require update to reflect current design or process parameters. Each review will be based on a standard review checklist (Site Form A-6002-395) and will be augmented by alternate calculations, whenever necessary to highlight a critical point or issue. A major objective of each review will be to explicitly verify calculations that have used to substantiate system performance and/or safety requirements. The Safety Class Helium (SCHe) system, which has been given the highest priority, will be reviewed first. Subsequent reviews will focus on each of the following systems (with descending priorities): Process Water Conditioning (PWC), Chilled Water (CW), Tempered Water Cooling (TWC), Vacuum Purge System Chilled Water (VPSCW), and the Tempered Water (TW) (lowest priority). The reviews will be summarized and documented within a written report to the CVD Facility design authorities in accordance with documentation guidelines for verification reporting in AP$027-00$. 
A completely independent network model of the Safety Class Helium system (SCHe) was completed using FATHOMs; a PC based flow network analysis program. The SCHe flow network included all four purge lines, four Helium supply systems, two process vent systems, and a detailed network model of the process hood and MCO internals. In addition, numerous pressure reducing valves, pressure relief valves, and check valves were modeled to allow various combinations of pressure setpoints to be investigated. Each of the valves can be turned on or off to force flow through various systems and network legs. In addition, pressure drop data from a series of MCO tests was used to develop a single overall loss coefficient $(\mathrm{K})$ versus flow for the $\mathrm{MCO}$. This allowed the development of a simplified network model. The purpose of the SCHe analyses was to determine if the Helium systems would provide the required design specification flowrates for three postulated conditions.

A letter documenting the review and the results of the independent calculations is currently being written.

\subsection{SIMULATION REVIEWS AND UPDATES}

Verification of previously performed simulations have been recently completed and issuance of revised reports are pending. These simulations have been examined and reexecuted based on results obtained during first article testing. The results of the reviews are found in the following reports:

Hanford Spent Nuclear Fuel Cold Vacuum Drying Process Goth-SNF Model Simulations of Normal Operations, EDT-623994 (JMI-98030105-1) B. C. Fryer, M. J. Thurgood, JMI, Richland, Washington.

Hanford Spent Nuclear Fuel Cold Vacuum Drying Process Goth-SNF Post-Test Simulation and Evaluation of Equipment (JMI-98030102-2) B. C. Fryer, M. J. Thurgood, JMI, Richland, Washington.

\subsection{INFORMAL REVIEWS}

In conjunction with preparation for the Comprehensive CVD Design Report, a significant amount of informal document review and comparison is being performed. The purpose of these reviews is similar to that being performed in the formal review, that is, comparison of various engineering media to insure consistency. The following reviews are being performed and will be formally documented by written report. They will be completed at the time of final release of the CVD Facility Comprehensive Design Report.

\begin{tabular}{|c|l|}
\hline $\begin{array}{c}\text { Person Performing } \\
\text { Review }\end{array}$ & Review Performed \\
\hline Ron Yanochko & $\begin{array}{l}\text { Comparison of Functions and Requirements Document to } \\
\text { Design Requirements Document Rev. 4 }\end{array}$ \\
\hline Rick Lodwick & $\begin{array}{l}\text { Comparison of Design Requirements Document Rev. 4 to } \\
\text { System Design Descriptions }\end{array}$ \\
\hline COGEMA Staff & Comparison of System Design Descriptions to Drawings \\
\hline
\end{tabular}


SNF-4396, Rev. 0

\begin{tabular}{|c|c|}
\hline COGEMA Staff & Comparison of FSAR to System Design Descriptions \\
\hline COGEMA Staff & Comparison of Drawings to System Design Description \\
\hline J. Frederickson & $\begin{array}{l}\text { Comparison of Engineering Flow Diagrams to Process Flow } \\
\text { Diagrams }\end{array}$ \\
\hline Carol Pitkoff & $\begin{array}{l}\text { Comparison of Construction Spec to Design Requirements } \\
\text { Document }\end{array}$ \\
\hline Brent Crea & $\begin{array}{l}\text { Comparison of Process Flow Diagrams and Engineering } \\
\text { Flow Diagrams to Specifications }\end{array}$ \\
\hline Floyd Maiden & $\begin{array}{l}\text { Comparison of Procurement Specs to Design Requirements } \\
\text { Document }\end{array}$ \\
\hline
\end{tabular}

\subsection{CONTROL AND VERIFICATION OF DESIGN CHANGES}

Design changes may be required as a result of the verification activities identified. Design changes may be required to correct errors and omissions or to improve the system or process. Design verification of changes is described in AP-027-00, and will be performed on all design changes. Verification will include an evaluation of the effects of the changes on the overall design and on any affected design analyses and verification that the analyses are still valid. If a modification to the verified design is required, the specific process will be used.

- Review proposed change against existing interface agreements. If an agreement is impacted, all affected parties must review and accept the change with a new or revised interface agreement produced.

- Perform a "USQ"-like screen (screening similar to an USQ in an operating facility) against the Safety Basis.

- If screen is positive, an in-depth verification will be performed, including review of potentially impacted hazards and accident analyses. This will be referenced in Block $14 \mathrm{~b}$ of the ECN form (or equivalent project type document) to design verification documentation. In this case, peer review will be conducted by an individual from the Nuclear Safety Organization.

- If screen is negative, verification must show that the performance parameters (defined in the Functions and Requirements document), applicable code requirements, design parameters and constraints, material properties have been considered and are still be met. This will be documented on the ECN Form in block $14 \mathrm{~b}$ (or equivalent project type document). For example, if a pump is under review, performance parameters such as flow and pressure should be stated. Review of a segment of pipe likewise must consider flow volume given an inlet flow and pressure and deliver an outlet flow and pressure. A hoist review will state a required lift capacity. Note that performance parameters are not the maximums that the SSC being modified was capable of, but is the demand output (flow, capacity, pressure, etc.) required to continue to support the overall system in meeting the system performance requirement. 


\subsection{AS-BUILT TEST AND INSPECTION PLAN AND SCHEDULE}

Following definitive design verification by means of the CVD Comprehensive Design Review, validation of the as-built system will be performed as the facilty and equipment are being accepted, delivered, and installed in the K-Basins. These test activities are described below. Details of the test schedule is found in Table 1, and are defined as Factory Acceptance Tests (FATs), Construction Acceptance Tests (CATs), and PreOperational Acceptance Tests (PATs). SNF program guidance and planning for testing is found in HNF-SD-SNF-TP-036, SNF Cold Vacuum Drying Test Specification and Test Plan. Guidance for startup testing (CATs and PATs) is provided in HNF-SD-SUP-003, SNF Startup Plan. Acceptance criteria for each test element are contained in the individual test procedures. Test and inspection activities will be as described below.

\subsection{FINAL CONSTRUCTION/EQUIPMENT INSTALLATION}

Equipment fit-up and installation will be validated during final construction and equipment installation by the CVD project team. At this time, walk-throughs will be performed to validate the as-built facility and equipment against the drawings. Design errors/omissions may be identified and documented at that time. Any changes to design media required as a result of findings during installation will be made in accordance with AP 6-027-00, SNF Project Design Verification Requirements.

\subsection{STARTUP TEST ACTIVITIES}

The CVD Facility startup function is an engineered sequence of inspection and test activities that culminate with successful project Startup. The Startup function, including the testing described, is managed and directed by the CVD Startup organization. They support the preparation and implementation of tests performed to confirm that CVD Facility meets all design and operational specifications for normal and off-normal condition, as defined in the SNF Startup Plan. Startup testing that provides significant design verification and validation and includes FATs, CATs, and PATs. FATs and CATs are primarily component tests and will be performed by the construction contractors and equipment vendors.

\subsubsection{FACTORY ACCEPTANCE TESTING}

Factory acceptance testing will be performed by the equipment vendor prior to equipment delivery. A listing of planned FATs, including type of and schedule for test is shown in Table 1. 


\subsubsection{CONSTRUCTION ACCEPTANCE TESTING (CAT)}

Construction acceptance testing (CAT) will be performed by the construction contractor to verify that construction is completed in accordance with all drawings and specifications and that equipment is installed correctly. Each subsystem or component CAT is governed by a CAT procedure. CVD Facility CATs will require electrical and mechanical connections to be verified, energized, and tested. Control circuits will be verified. Equipment and instrument loop calibrations will be performed. Piping will be flushed and leak tested, and relief valves tested and calibrated. HVAC systems will be structurally and pressure tested, and balanced. Details of the individual CATs and acceptance criteria for each can be found in the specific procedure of interest.

\subsubsection{PREOPERATIONAL ACCEPTANCE TESTING}

Pre-operational acceptance testing will follow construction acceptance testing. The PAT combines post-construction acceptance testing with operational testing that will be used to validate the design basis and demonstrate correct function of all systems during normal and off-normal conditions. PATs will be performed before hot run testing using stimulants similar to those used in first article testing. The PATs will address operational stability and control of systems, designed transients and postulated accidents, and loss of power testing. PATs include operation of both individual and integrated systems in manual and automatic modes, demonstration of permissive and lockout functions, computer and software verification, mechanical system operation in normal and upset modes, HVAC and HEPA system testing, and stack monitoring checkout.

For details of test requirements and acceptance criteria for each PAT, refer to the individual test procedure. A listing of all CVD Facility system PATs, including test specification references and planned test dates is included in Table 1.

\subsection{PROCESS VALIDATION DURING INITIAL OPERATION}

Process validation occurs at the beginning of production. During processing of the first $24 \mathrm{MCOs}$, detailed measurements and further validation of the CVD process will be made using actual fuel. Although this occurs as part of operations, and is therefore beyond the time in which V\&V normally occurs, data collected may be used to further refine process methodology. Process parameters may be adjusted for optimal performance during this final process validation. The requirements for final process validation are defined in SNF Process Validation Requirements, HNF-SD-SNF-CN-027. Measurements will include the following: 


\subsection{BULK WATER REMOVAL RADIATION LEVELS}

Measurements will include:

- Neutron and gamma surveys of the cask before and after water is drained from the $\mathrm{MCO}$,

- Neutron and gamma surveys of the process lines and Process Water Conditioning lines and equipment before, during and after the water is drained from the $\mathrm{MCO}$, and

- Neutron and gamma surveys of the cask before and after water is drained from the cask annulus.

These measurements will be applied to the first four MCOs.

\subsection{CORROSION POWER TEST}

The hydrogen and xenon gas concentration in the MCO head space over the fuel will be measured after heating the water filled MCO to 35 and $50 \mathrm{C}$ at CVD and sparging the $\mathrm{MCO}$ with helium. These measurements will be used to calculate the oxidation reaction occurring in the MCO. This test will be applied to 12 selected MCOs.

\subsection{DRAINED WATER ANALYSIS}

Water samples will be taken from the feed to and the product of the IXM/filter used in CVD. These samples will be analyzed for both particulate and soluble radionuclides including TRU, Pu, Am, Cs, and Sr. These samples will be analyzed from 12 selected MCOs.

\subsection{GAS GENERATION RATE}

Hydrogen, xenon, and nitrogen gas concentration in the helium purge will be measured during drying under vacuum at $50 \mathrm{C}$ to determine the reaction rate constant for low pressure water vapor. These measurements will be made on 12 selected MCOs. 
SNF-4396, Rev. 0

APPENDIX A - CVD COMPREHENSIVE DESIGN REVIEW CHECKLIST 
SNF-4396, REV. 0



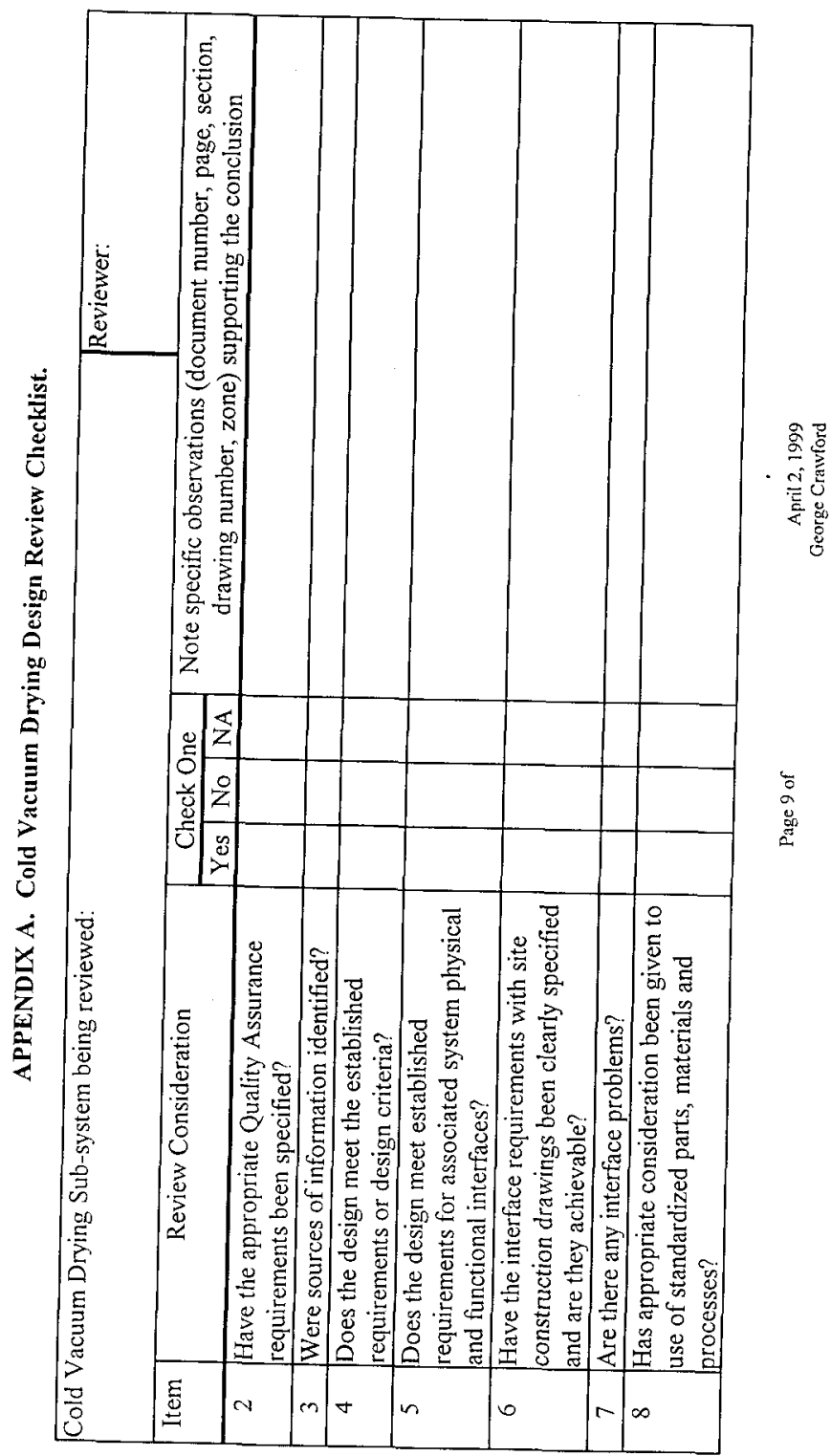


SNF-4396, REV. 0

焉

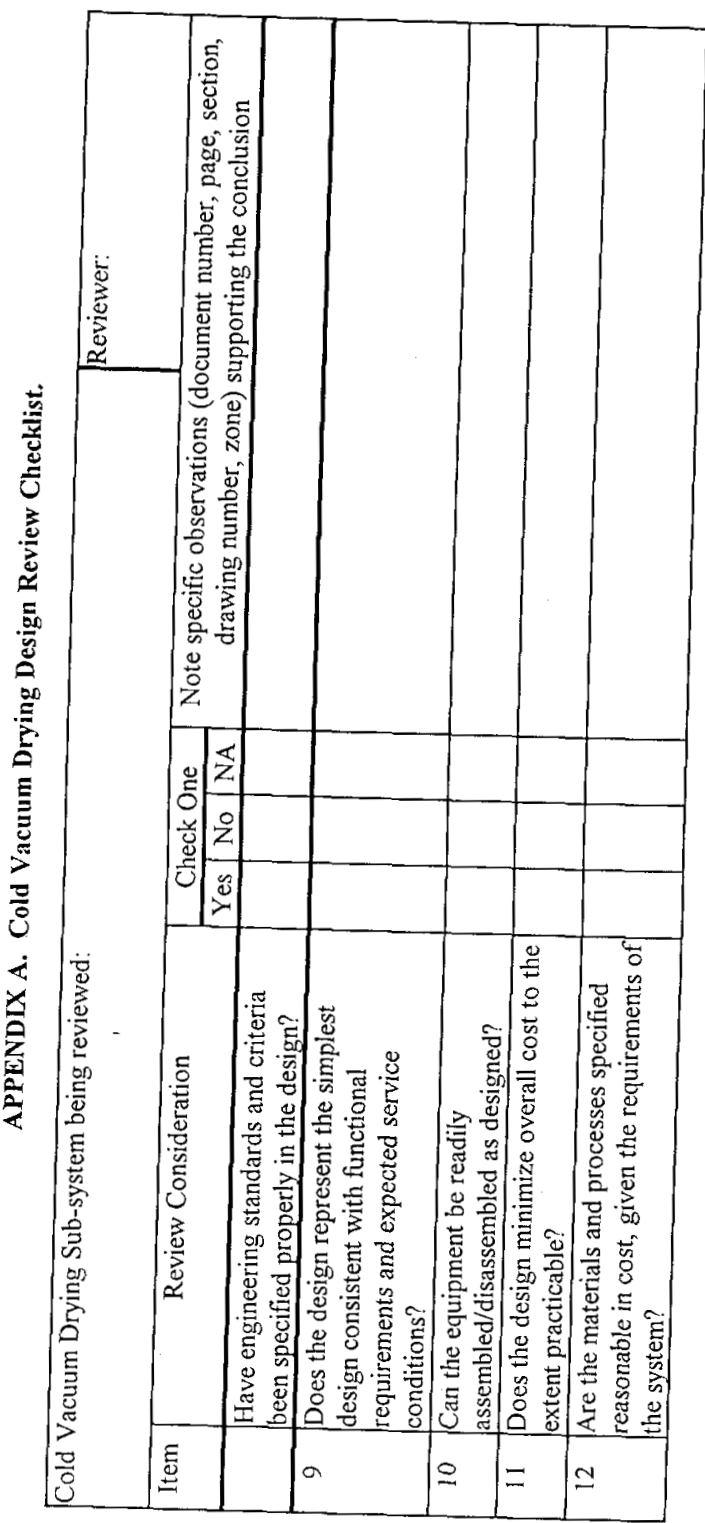

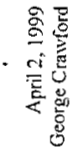

$\frac{5}{0}$ 
SNF-4396, REV. 0

ט్

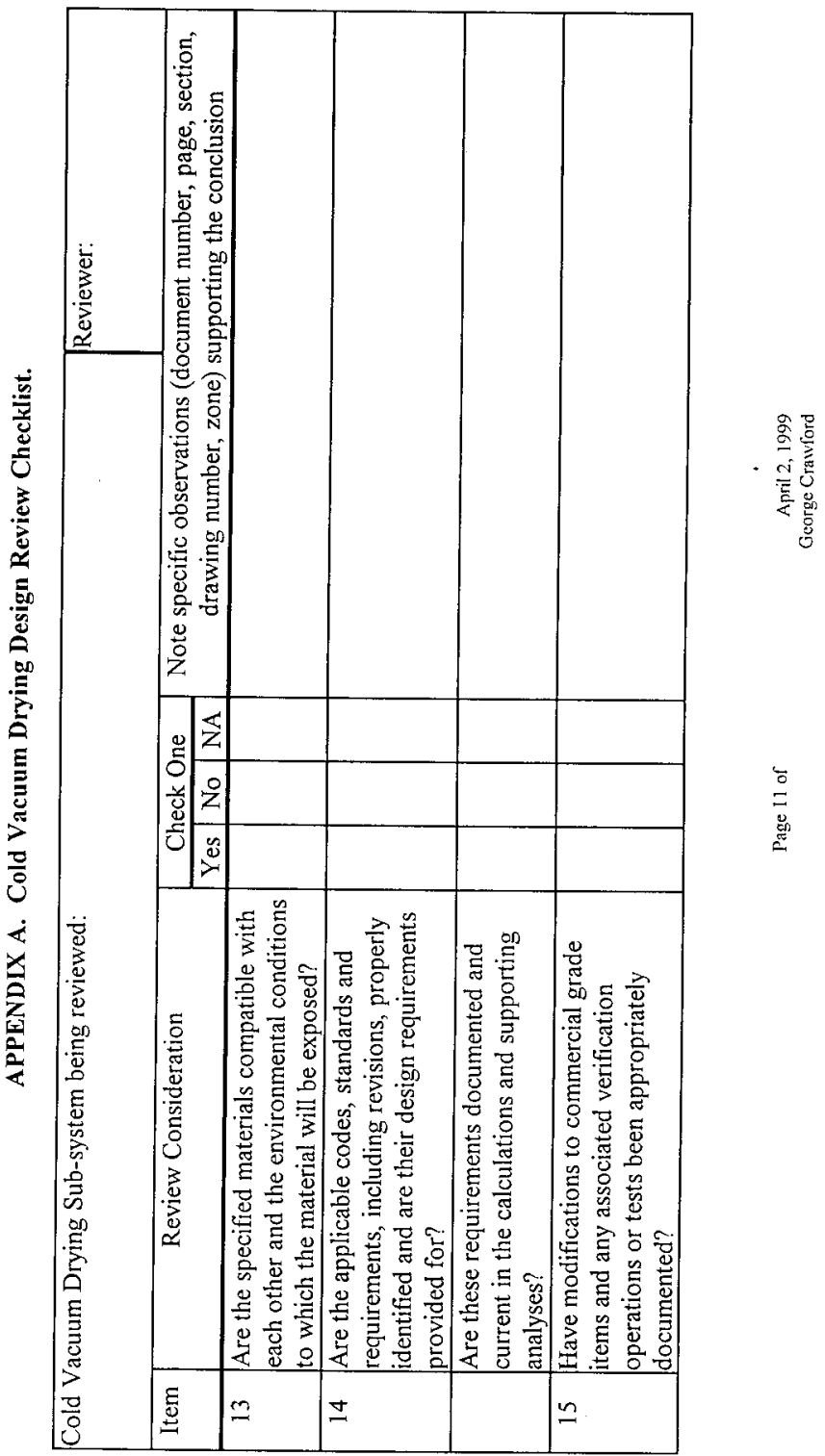


SNF-4396, REV. 0

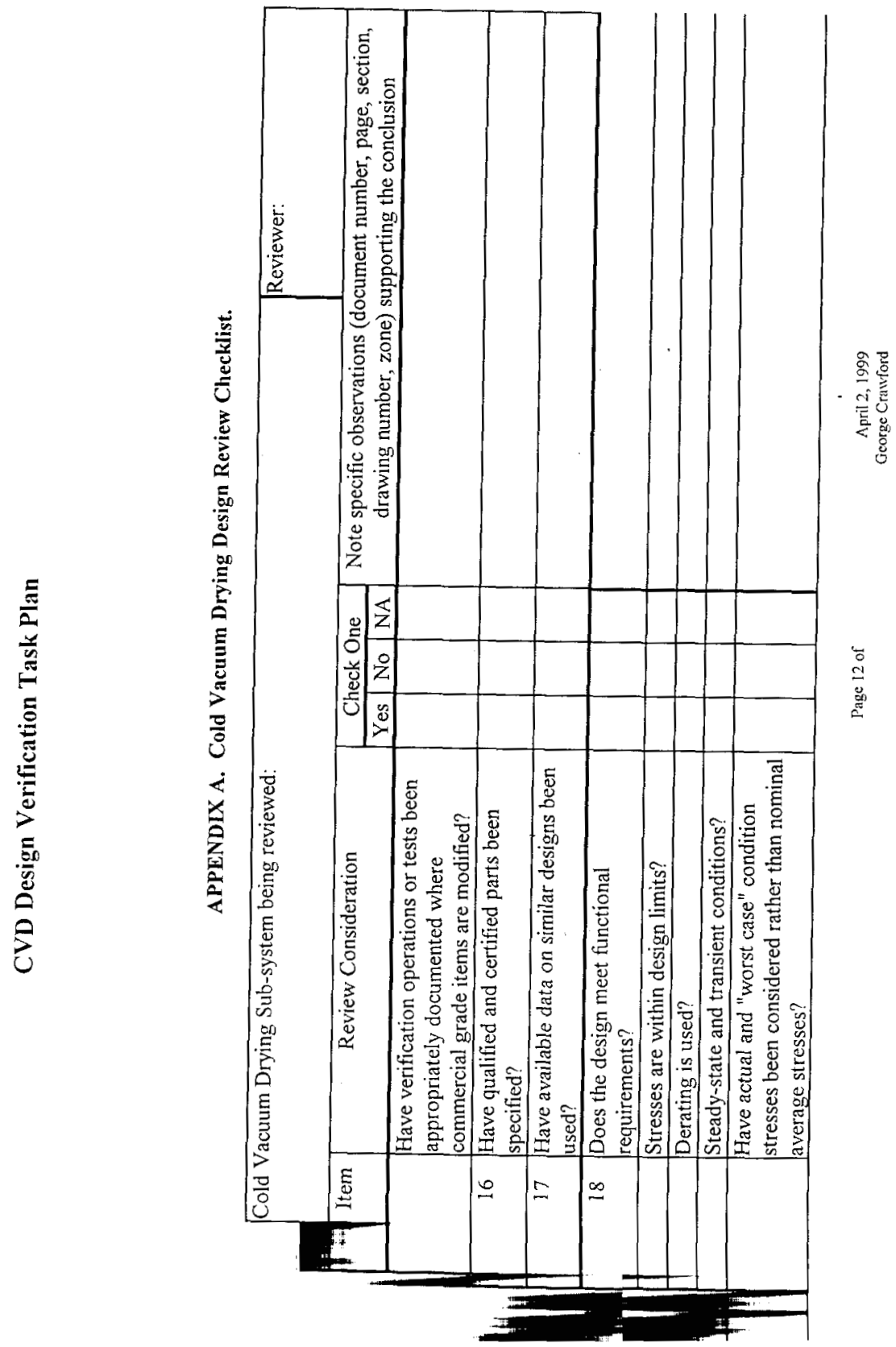


है

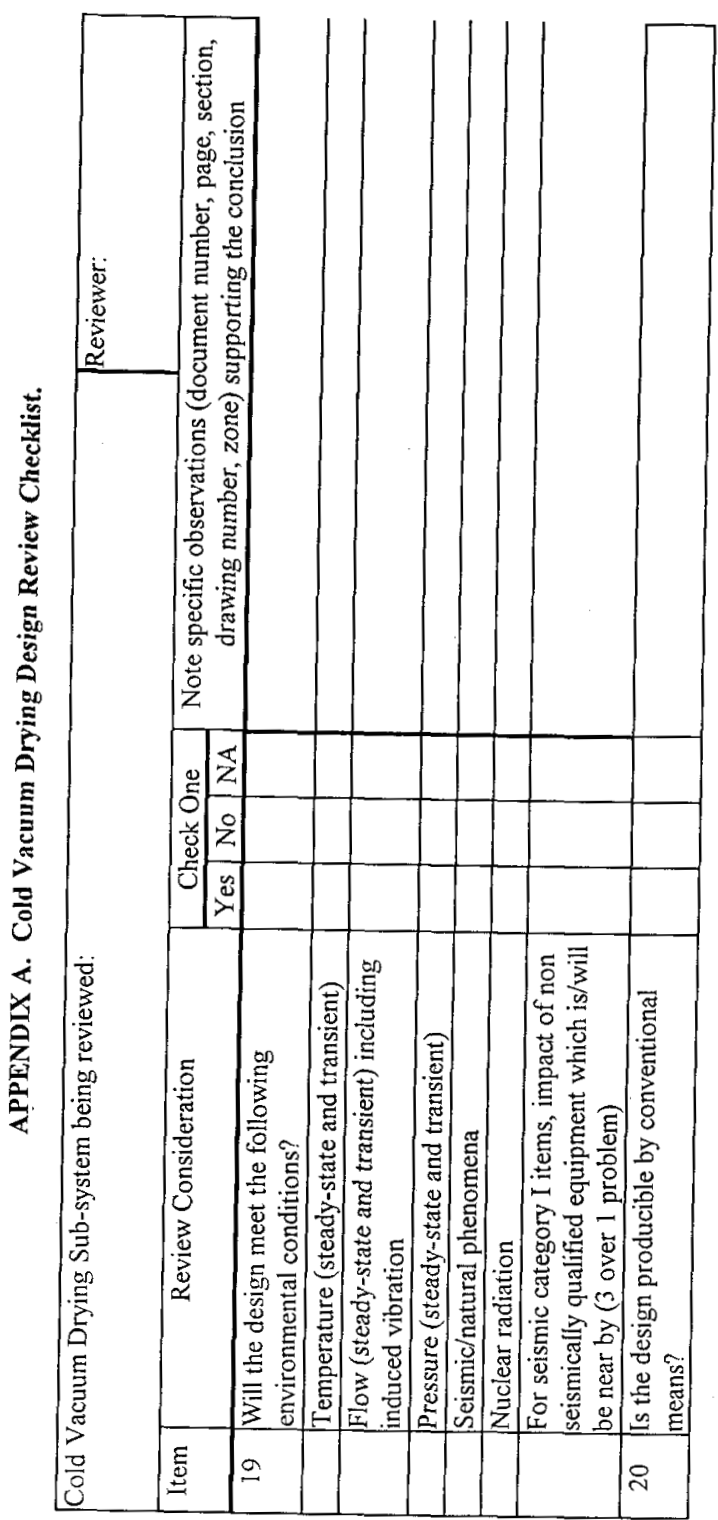

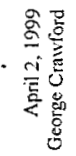

3
0
0
0
0
2 
SNF-4396, REV. 0



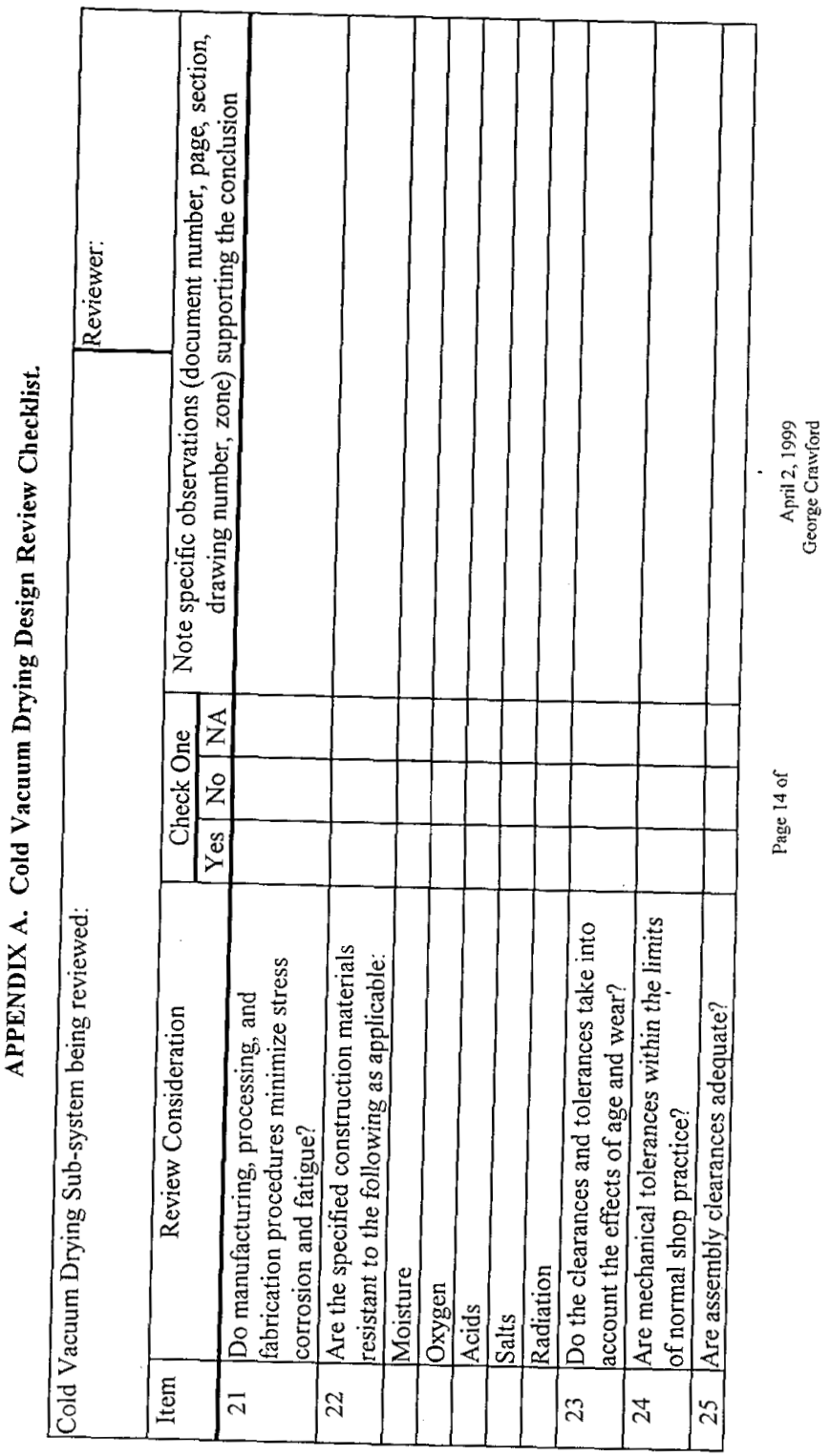


SNF-4396, REV. 0

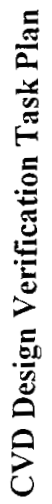

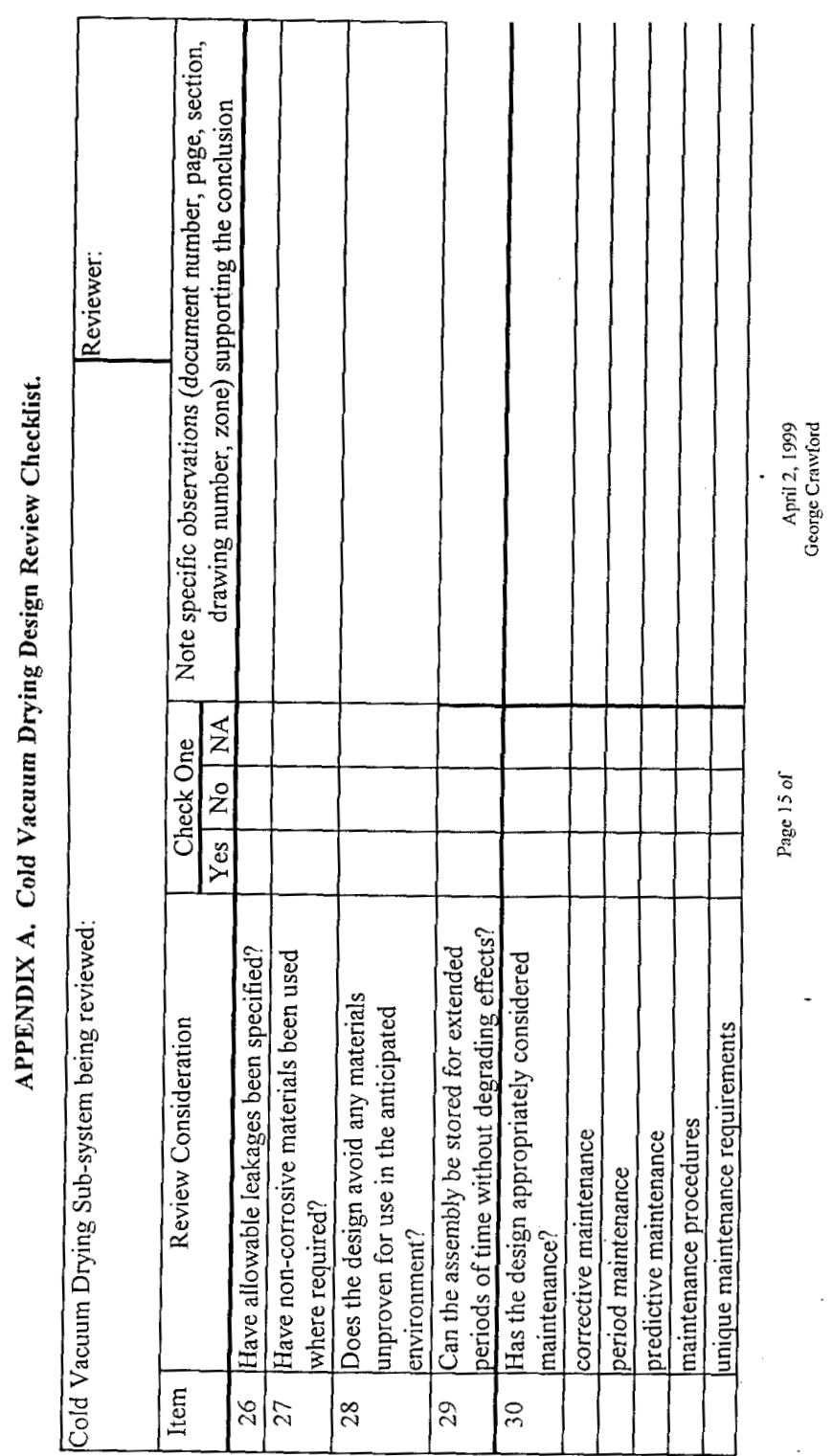


SNF-4396, REV. 0

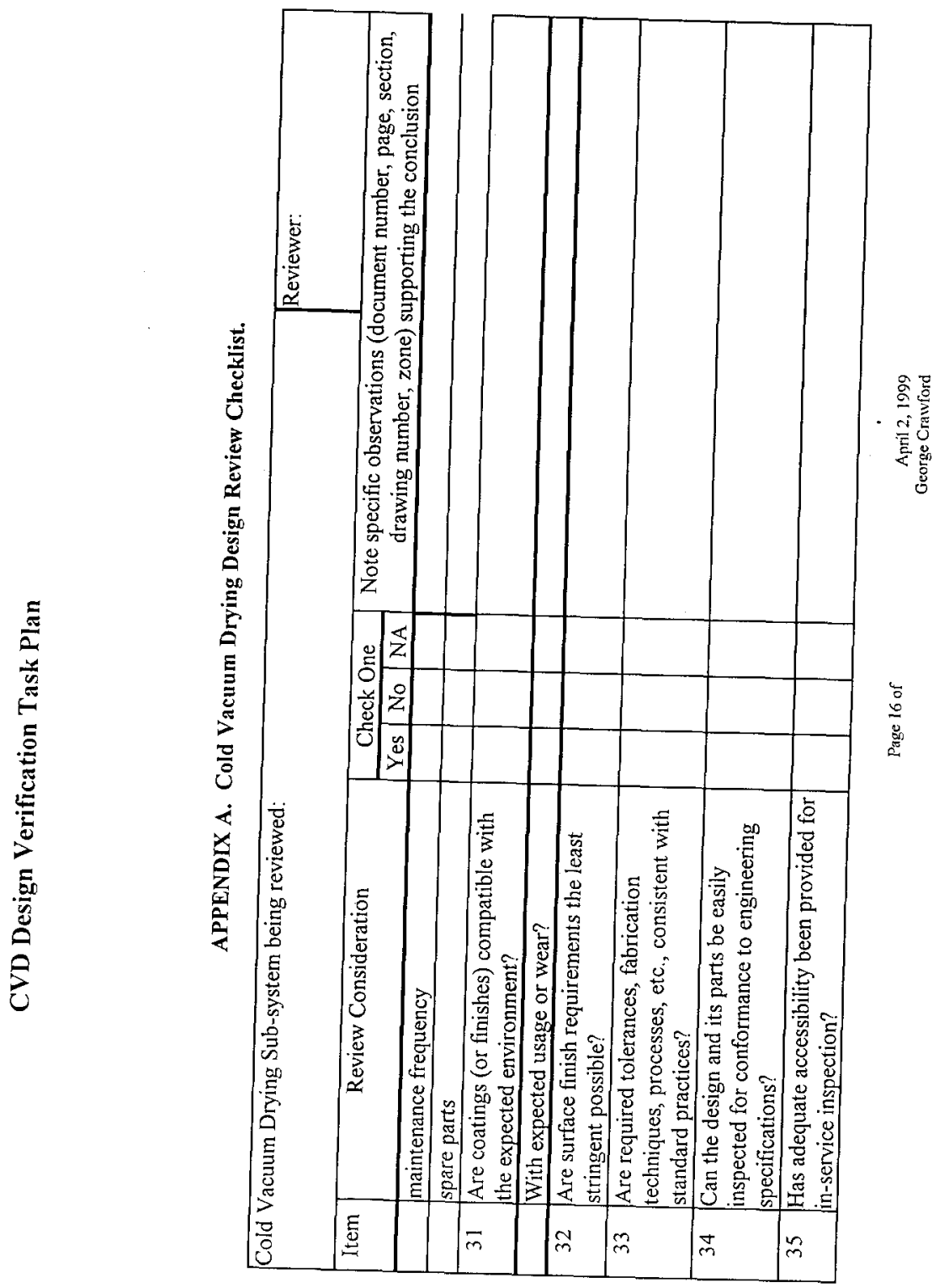


SNF-4396, REV. 0

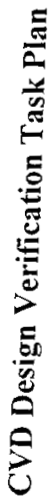

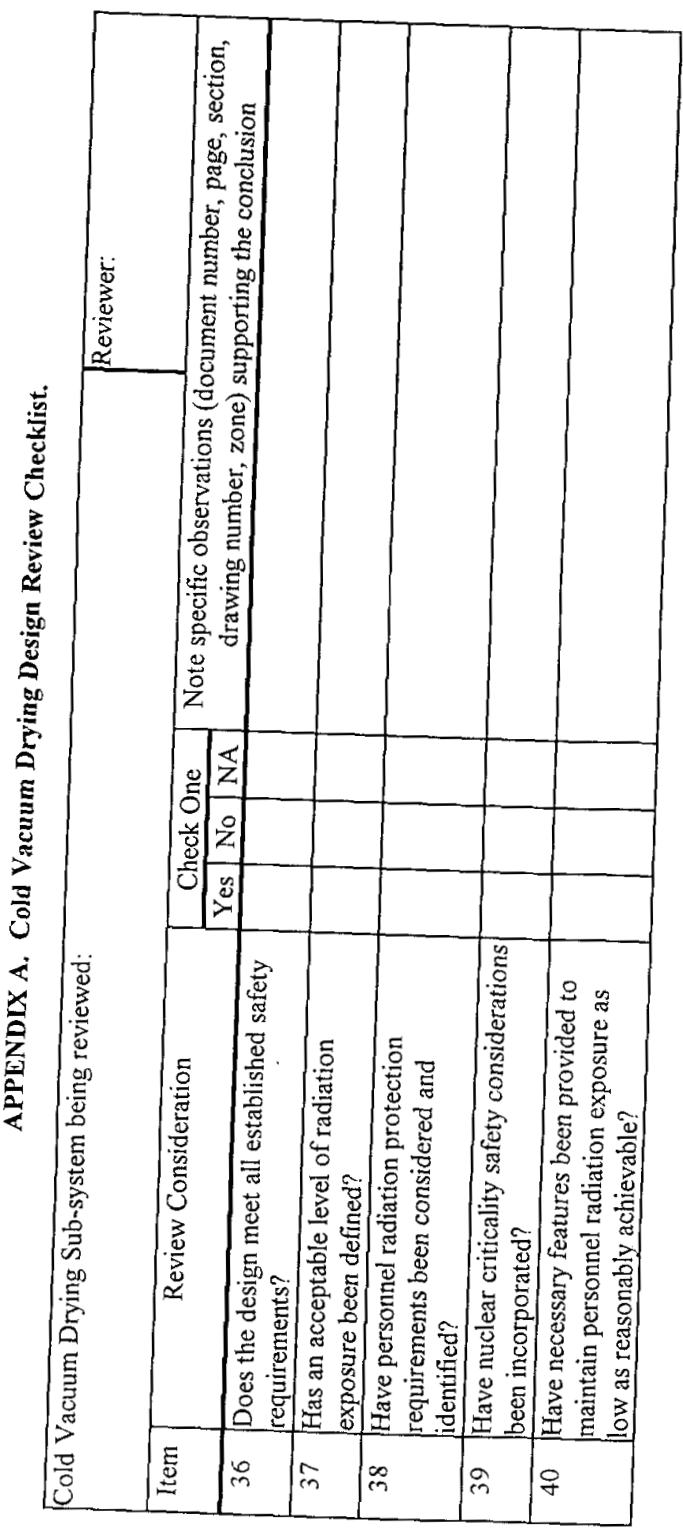

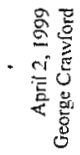

$\stackrel{5}{\circ}$ 
SNF-4396, REV. 0



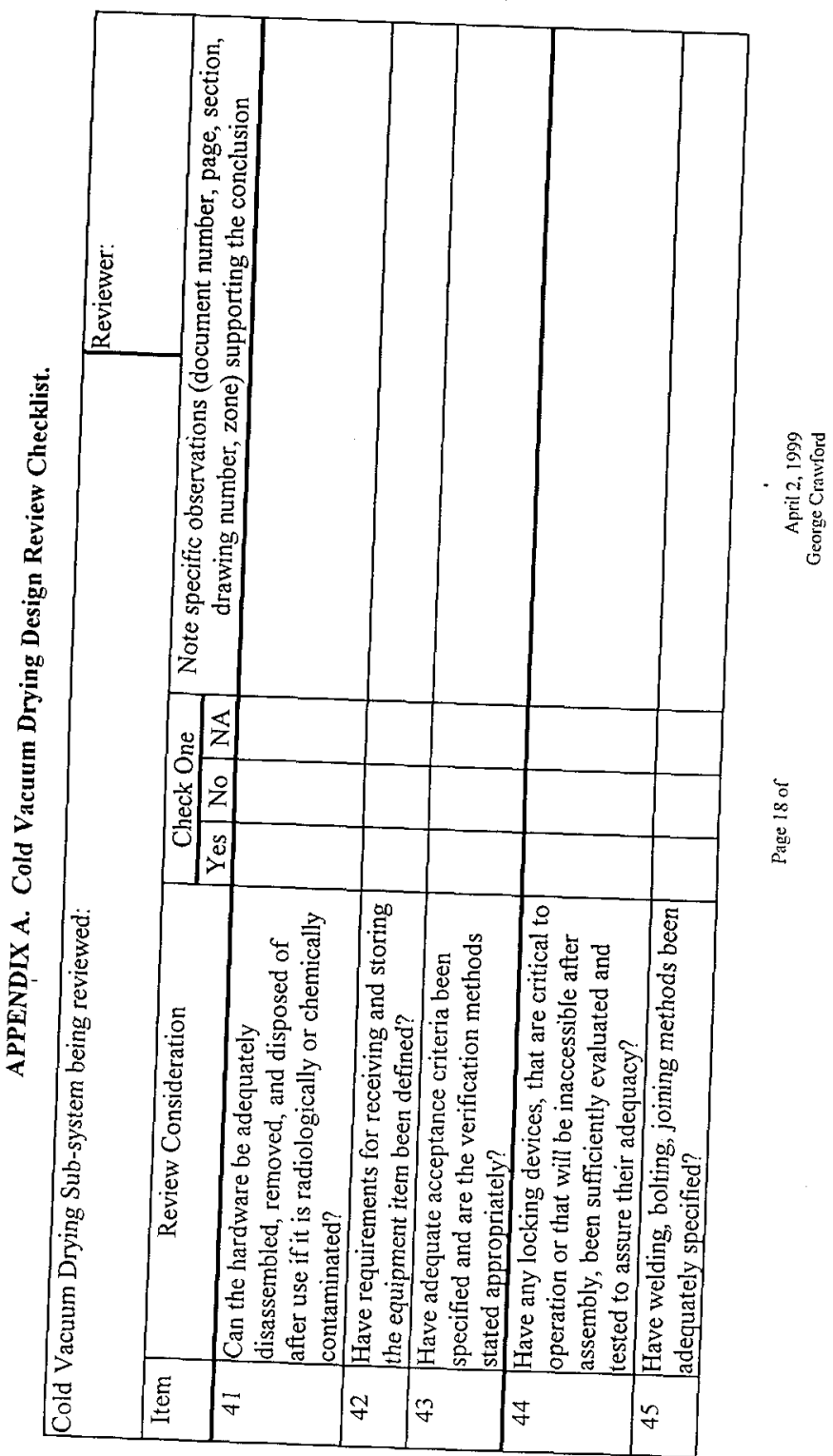


SNF-4396, REV . 0

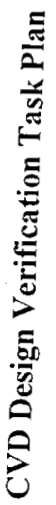

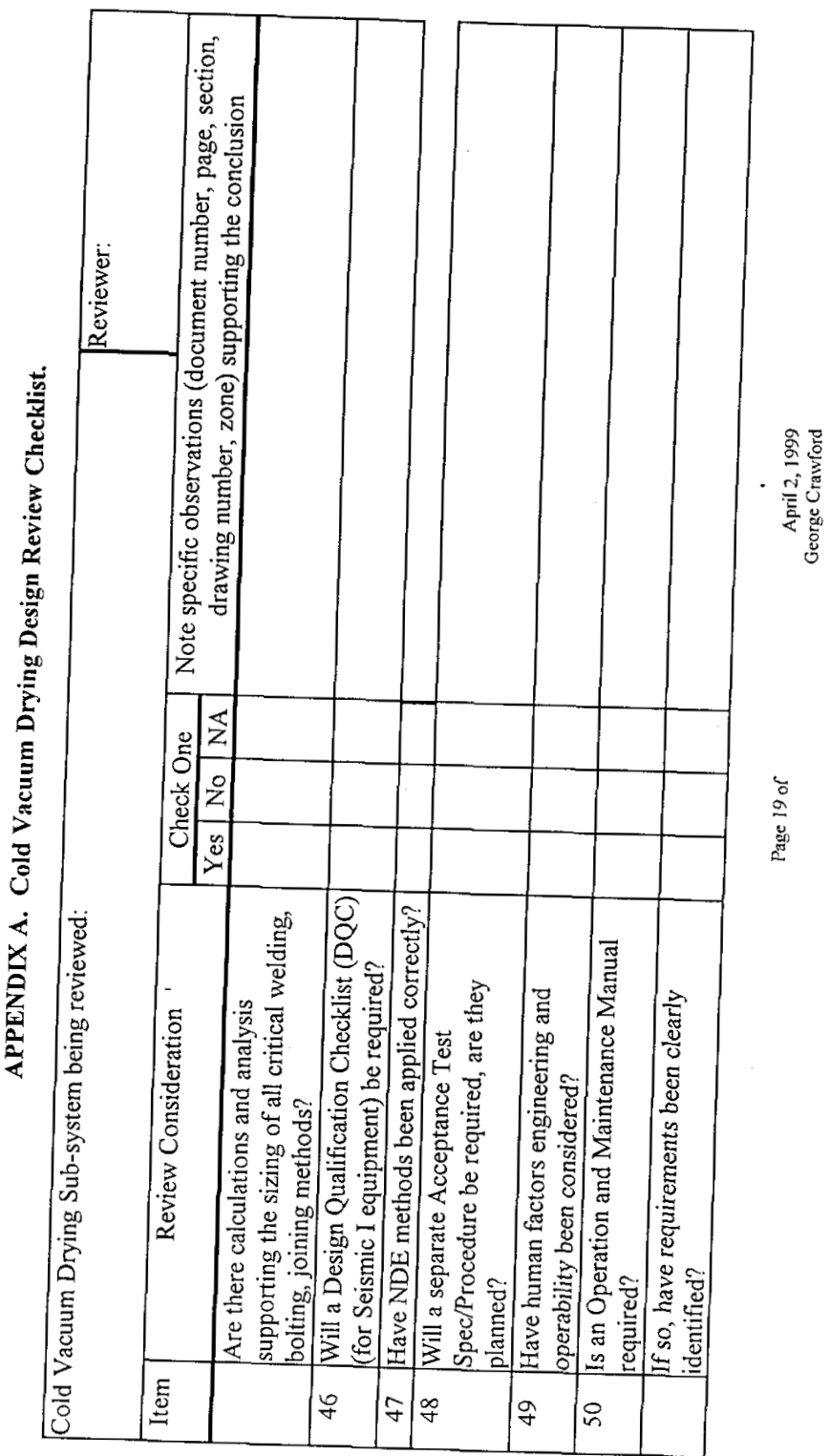


SNF-4396, REV. 0

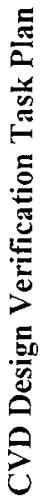

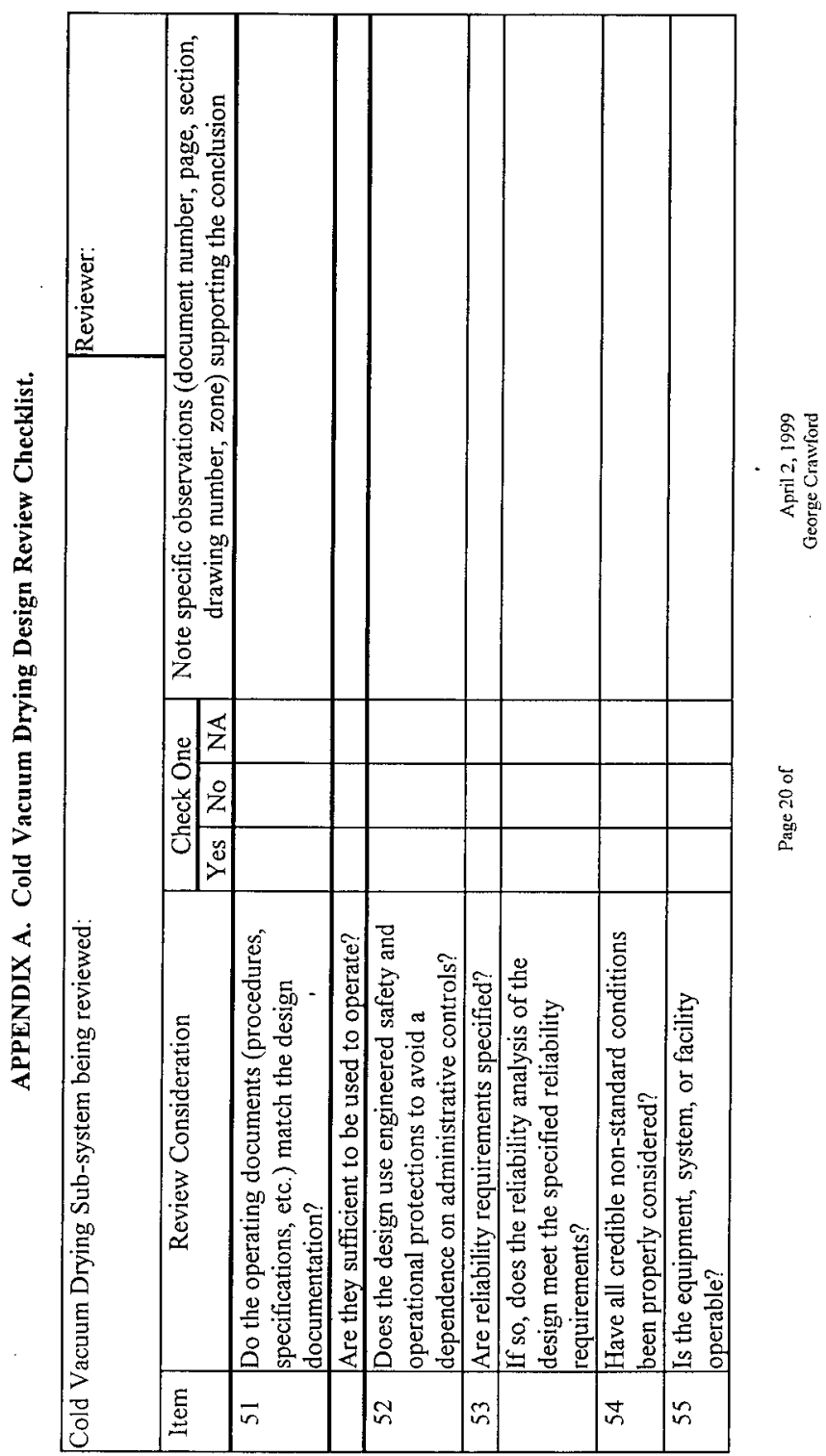


至

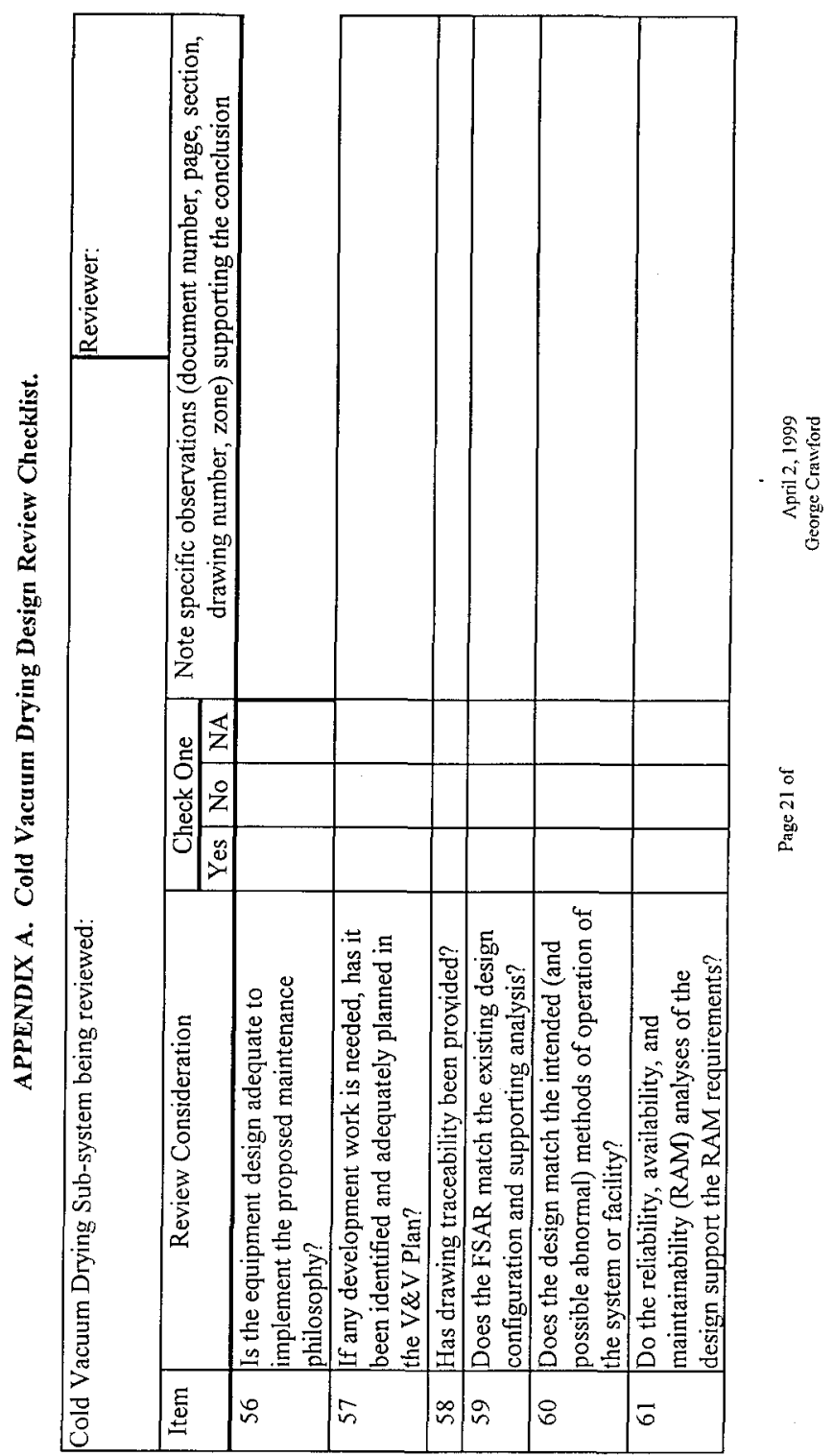


SNF-4396, REV. 0

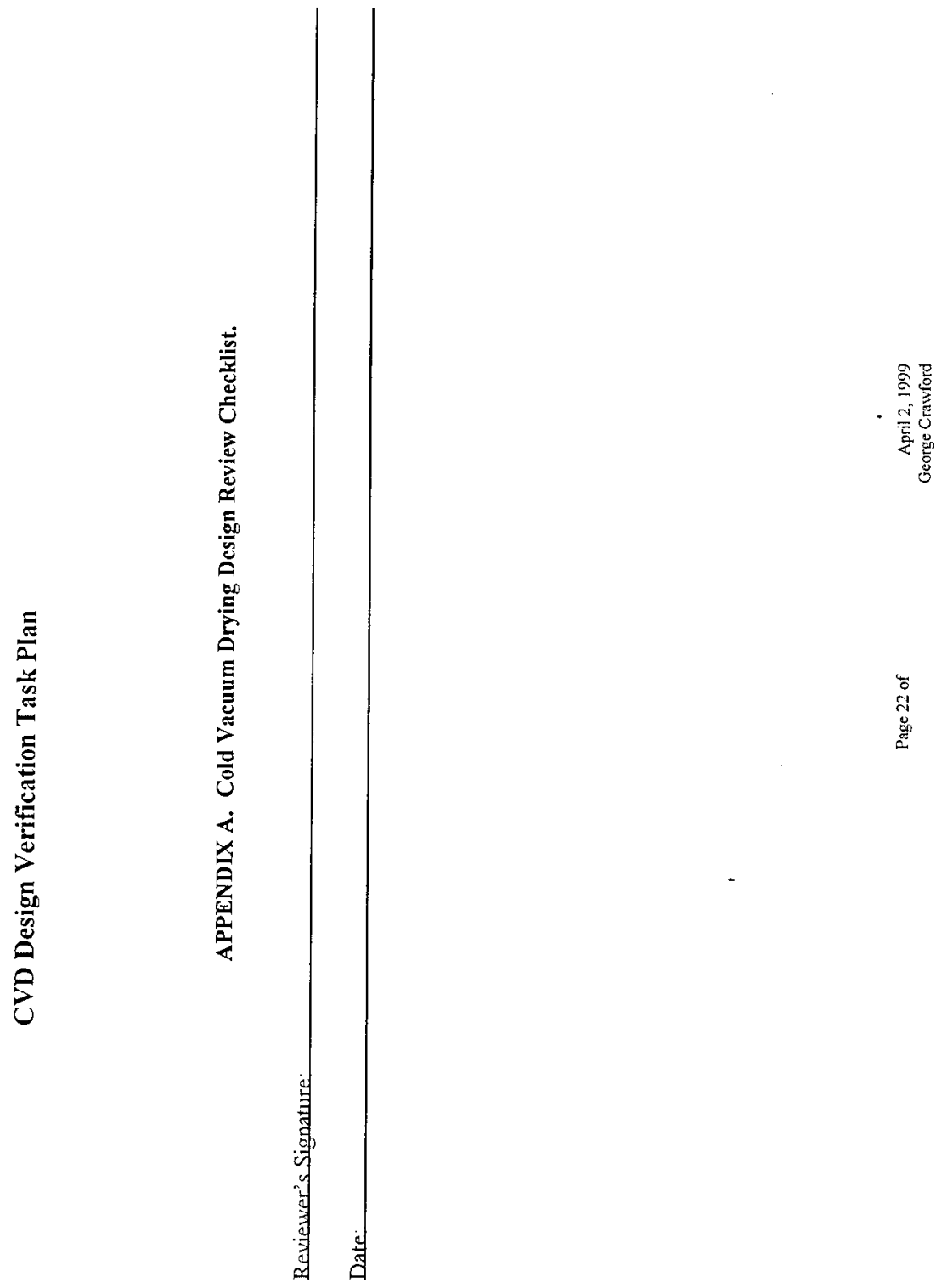


SNF-4396, REV. 0

Appendix B - Review Comment Record Form 
5)h-45yo, at.

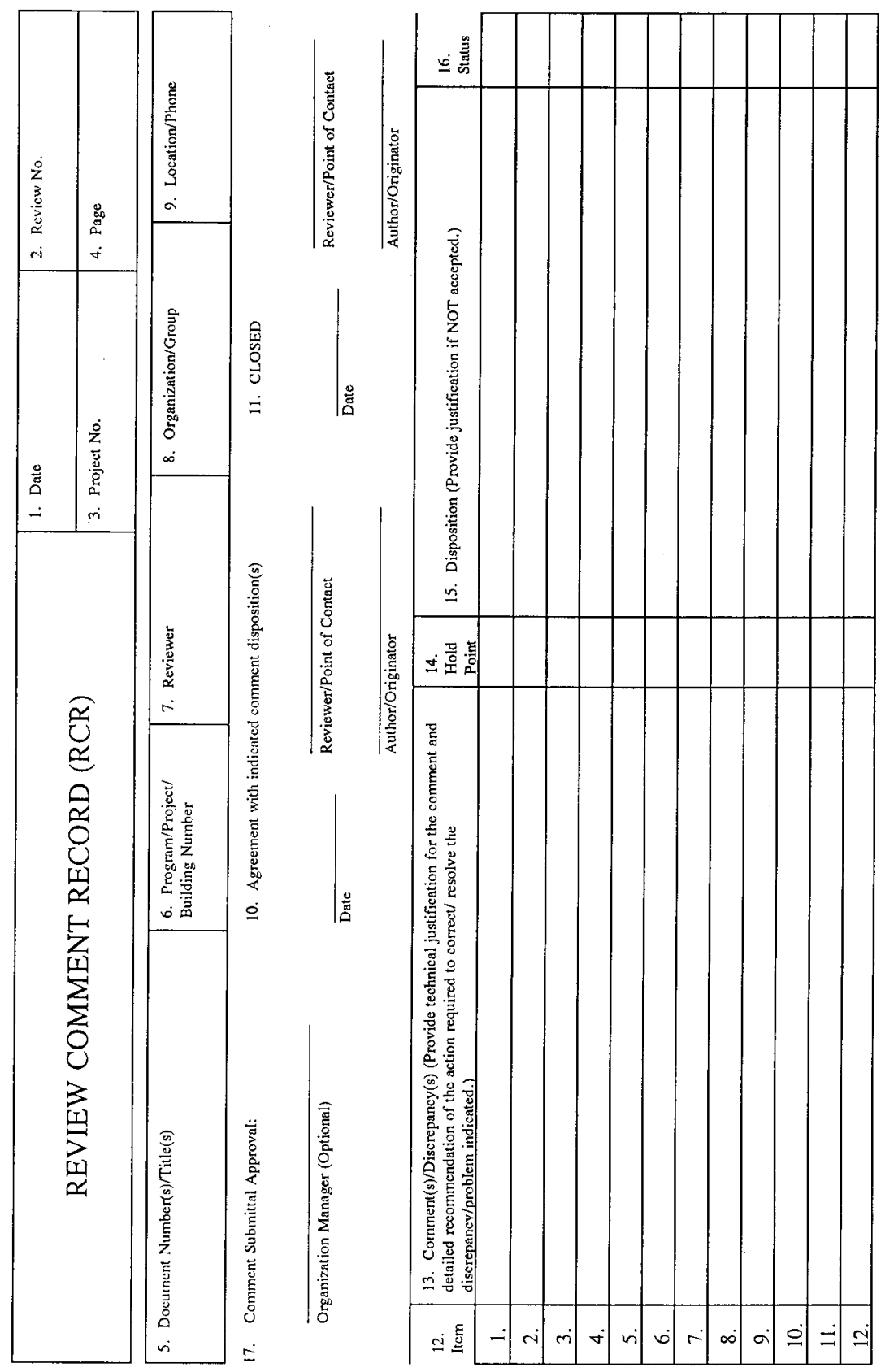

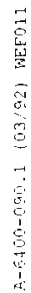




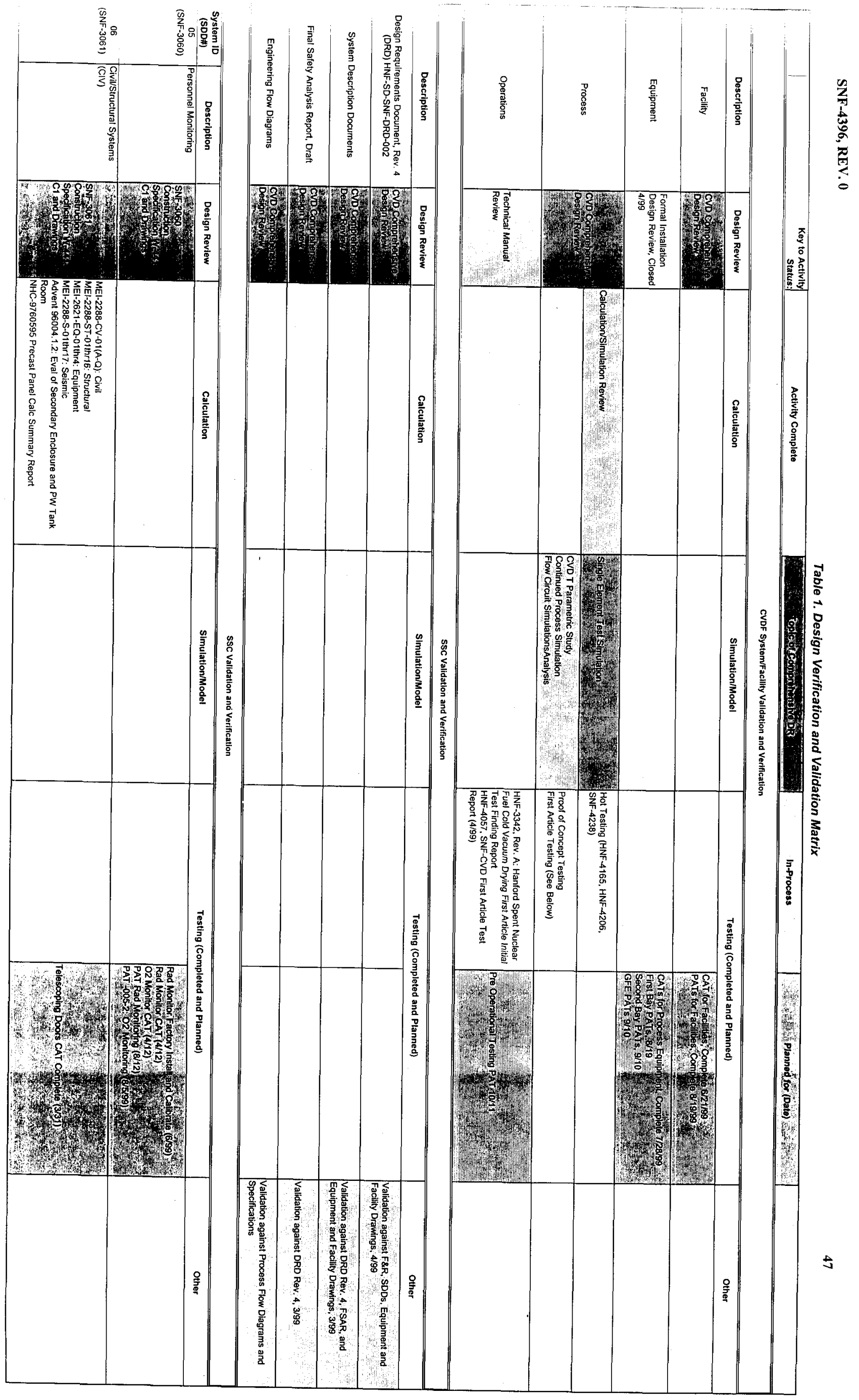




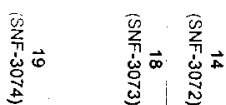

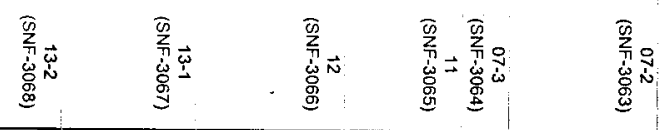

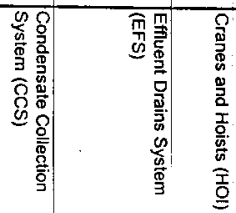

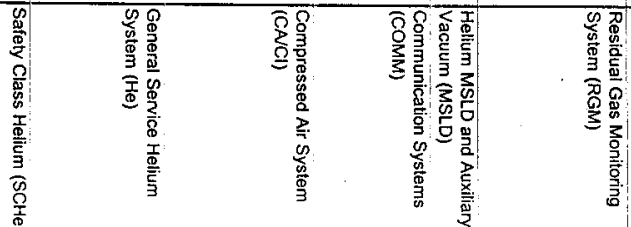

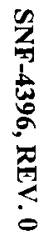

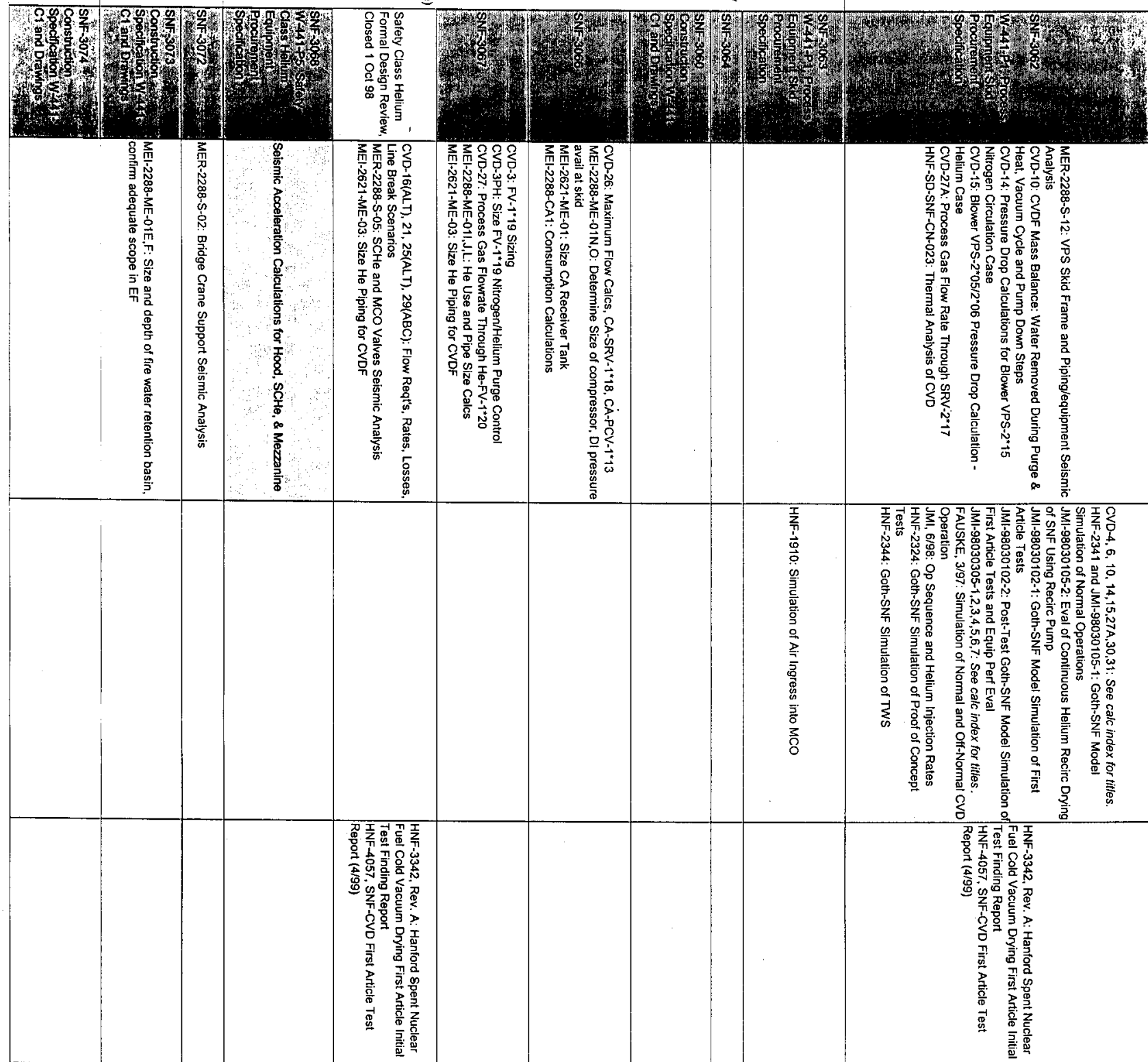

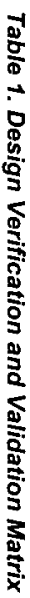

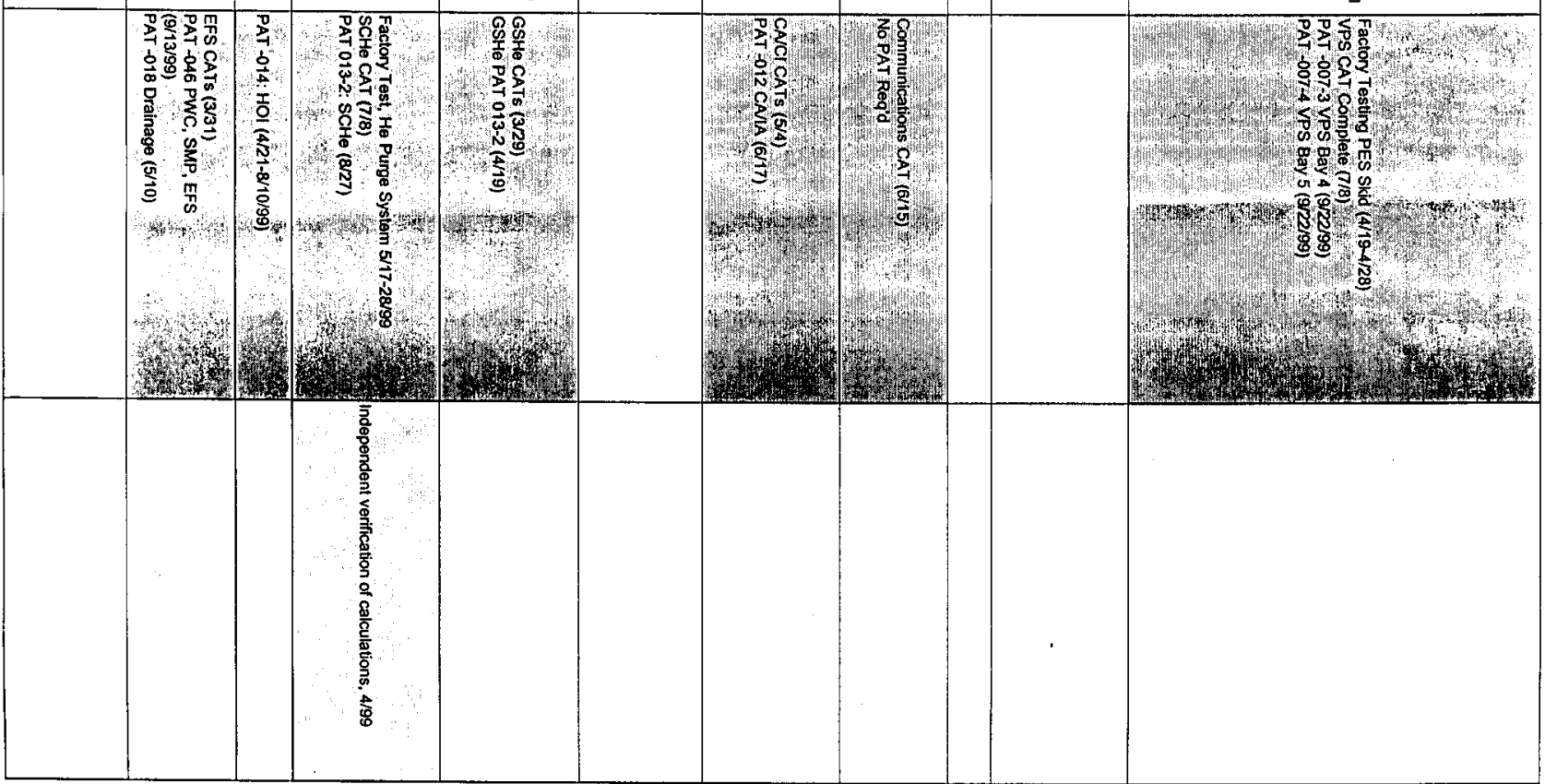




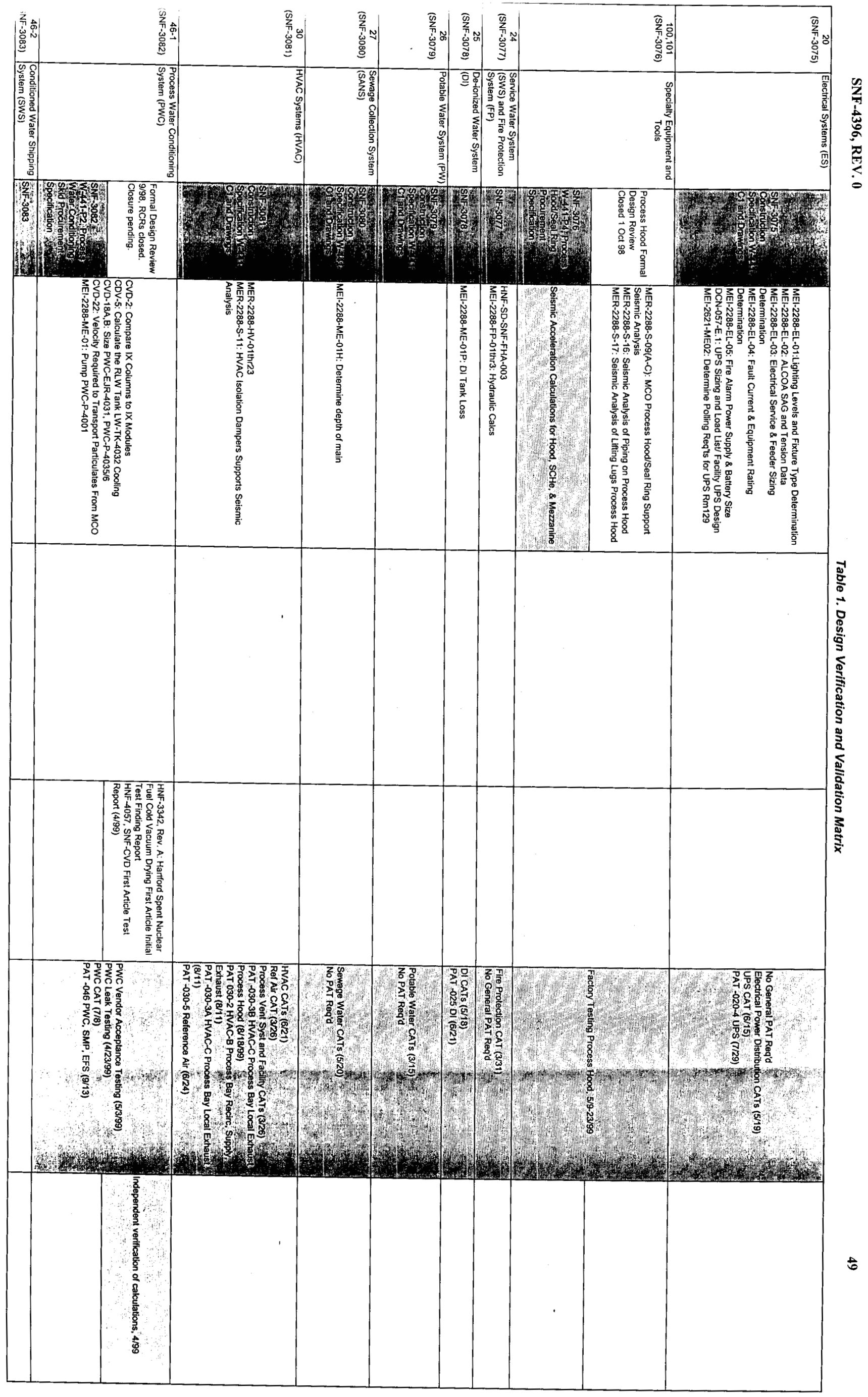




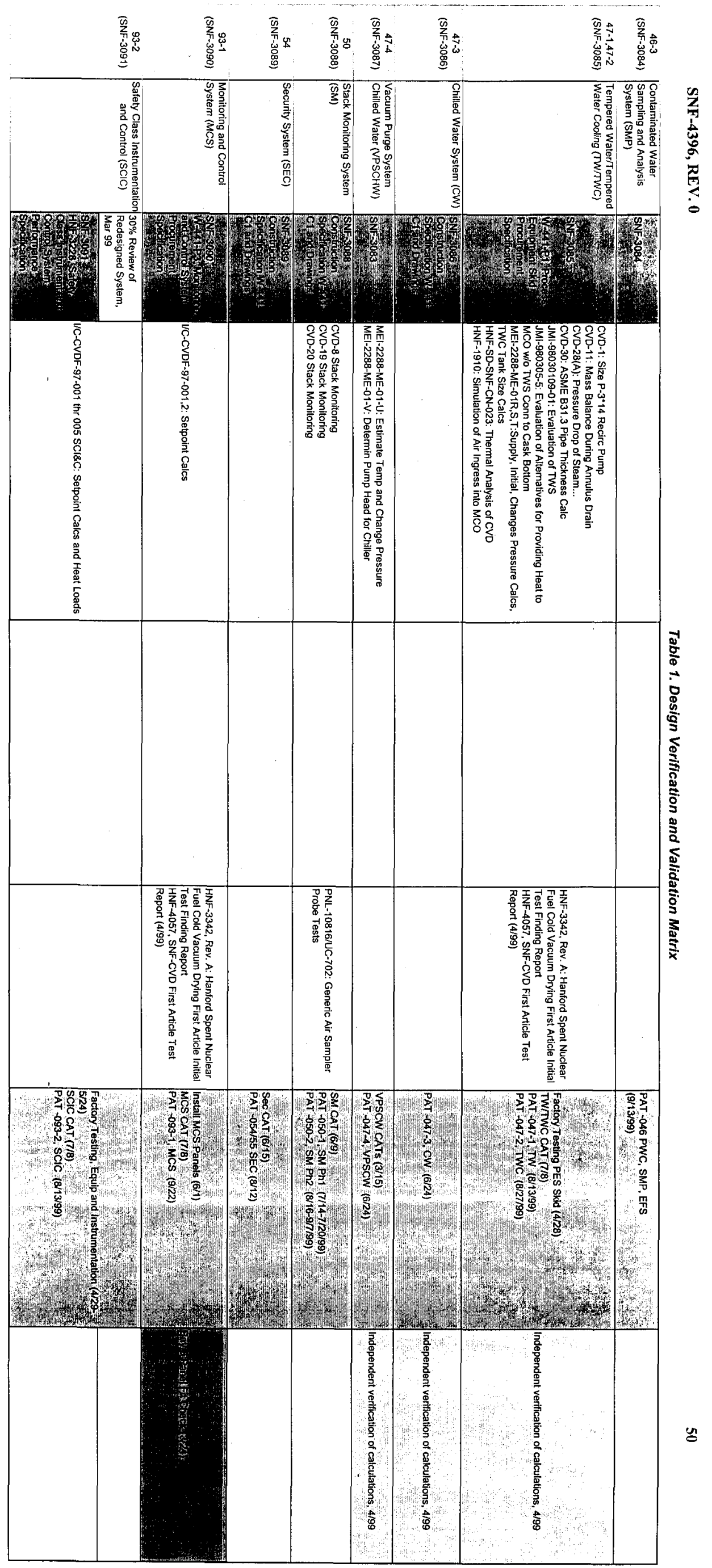

